DIVISION OF THE HUMANITIES AND SOCIAL SCIENCES

CALIFORNIA INSTITUTE OF TECHNOLOGY

PASADENA, CALIFORNIA 91125

PARIMUTUEL BETTING MARKETS AS INFORMATION AGGREGATION DEVICES: EXPERIMENTAL RESULTS

C.R. Plott

J. Wit, University of Amsterdam

and Visiting Associate at California Institute of Technology

W.C. Yang

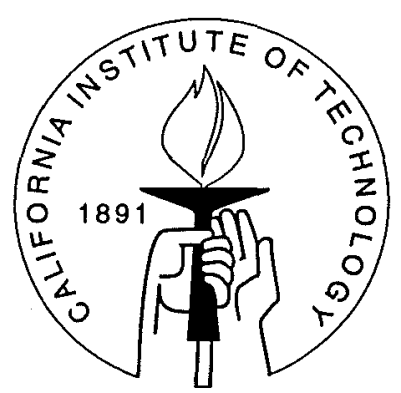

SOCIAL SCIENCE WORKING PAPER 986

April 1997 


\title{
PARIMUTUEL BETTING MARKETS AS INFORMATION AGGREGATION DEVICES: EXPERIMENTAL RESULTS ${ }^{1}$
}

\author{
C. R. Plott, J. Wit, and W. C. Yang ${ }^{2 \cdot}$
}

\section{INTRODUCTION .}

Markets have the capacity to aggregate information held diversely by individuals. Less than complete information held by various individuals becomes pooled and aggregated by the dynamics of the price discovery process. This capacity is not perfect and it appears to depend upon details of market organization and the instruments that are traded. Nevertheless such capacity exists and motivates a broader question about the existence of other institutions and organizations to perform this task. This study makes an inquiry about Parimutuel betting. Two broad questions are posed. ${ }^{3}$ (i) Is some form of parimutuel betting systems capable of aggregating diverse information? This question asks for a "proof of principle" in the sense of a demonstration that the aggregation property can exist and be observed as a part of a working process. (ii) Can any success or failure of information aggregation be understood within the context of standard models? This second question reflects a requirement of "design consistency". If something works we would like to know if it works for theoretically understandable reasons.

The origin of parimutuel markets lies in horse-race betting, where betters can buy tickets on every horse that runs the race. A parimutuel is a system of betting in which the winners divide the total amount bet in proportion to the amounts they bet on the winning horse. The word "parimutuel" comes from the French words "pari mutuel", meaning "wager mutual". Naturally occurring parimutuel betting systems are not designed as information aggregation devices. They are designed for entertainment and business purposes. Nevertheless, researchers have inquired about whether or not the odds that are endogenously determined by parimutuel betting are consistent with the relative frequency of winners. The data used in such studies are typically the amounts bet at horse racetracks, since these data tend to be available and the rules of the process are somewhat transparent because of regulation and inspections.

\footnotetext{
${ }^{1}$ The financial support of the Caltech Laboratory for Experimental Economics and Political Science and of the National Science Foundation is greatly appreciated. We wish to thank Colin Camerer, Dave Grether, and Markus Nöth for their comments and insights at the early stages of this research. In addition we wish to acknowledge the many useful comments provided by the seminar on experimental economics at Caltech and by Thierry Foucault. We also thank Ralph Miles for correcting an error regarding parimutuel terminology and John Patty for his comments on the manuscript.

${ }^{2}$ C. R. Plott is a Professor of Economics at the California Institute of Technology. J. Wit is a Ph.D. student at the University of Amsterdam and a visiting associate at the California Institute of Technology.

W. C. Yang is a junior at Caltech.

${ }^{3}$ These two questions reflect an evolving methodology for guiding research on mechanism design (see Plott, 1994).
} 
The remarkable result from the field studies of parimutuel betting is that the relative frequency with which horses win races is closely related to the odds that evolve endogenously through the betting process. Broadly summarized, this empirical literature ${ }^{4}$ has established the existence of a clear monotone relationship between prices (odds) and observed relative frequencies of winning. High priced bets, the favorites that pay low odds, win regularly whereas low priced bets, the longshots that pay high odds, win occasionally. The information found revealed in naturally occurring examples is not perfect. A "long shot bias" exists; the odds on long shots tend to be too high, but the bias is not "large".

The fundamental questions posed by this paper cannot be answered with field data. First, because the mechanisms found in the field are designed as entertainment devices, as opposed to information aggregation tools, there are both institutions and practices (race rigging, off track betting, etc.) that exert themselves to complicate any analysis.

Secondly, and more importantly, from the field studies it is impossible to determine if information aggregation is occurring. The information that is held by the individual agents is unknown to the scientist so the most fundamental of parameters needed for analysis is unknown. This parameter is unknown and probably is unknowable as a matter of principle. The information represented in the established odds might simply be the information held by a single individual or a group of individuals with identical private information. While data from field studies can be used to determine the accuracy of statistical expectations, the fundamental question about aggregation cannot be answered with the data.

Thus, the data and analysis produced by the experiments reported here are the first evidence that has been produced regarding the questions posed. Two experimental studies concerning parimutuel betting do exist (Hurley and McDonough, 1995; Peron and Smith, 1995) but they do not address the issue of information aggregation, leaving open almost all questions regarding information revelation as well. ${ }^{5}$

From a theoretical perspective it is not obvious why the parimutuel system should successfully aggregate information. The odds cannot adjust independently as do market prices since the odds on a horse go up only if bets are placed on other horses. Furthermore, there is substantial opportunity for bluffing and deception by placing bets on horses other than the horse one expects to win. An agent with the "correct information", having placed a bet on the "correct horse", can then bet on the "wrong" horses if such betting attracts the bets of others to the wrong horses. If such deceptive activity does attract the bets of others to the wrong horse, it will increase the odds on the correct horse, resulting in the insider getting all of his/her investment back plus the bets

\footnotetext{
${ }^{4}$ The empirical literature, Weitzman (1965), Rosett (1965), Ali (1977,1979), Snyder (1978), Asch, Malkiel and Quandt (1982), Thaler (1992), has a long history of testing various forms of the efficient market hypothesis. Generally speaking, it is not possible to make bets with positive expected profits after track commissions that amount to up to $20 \%$.

${ }^{5}$ In the first study there are questions regarding the consistency of the overall design and the incompatibility of the procedures with standard experimental economics, including payments, the limited number of real people, the lack of time structure in the parimutuel betting process, etc.
} 
of others. Thus, intuitive support can be found for a belief that incentives exist for agents to place incorrect information into the system and thereby frustrate any tendency the system might have for information aggregation and revelation.

Theory aside, the empirical relationships found in field studies suggest that the parimutuel systems found in the field might have information aggregation powers on average, and thus suggest the possibility of designing a parimutuel system that will perform the aggregation task. That is, if the motivation for the creation of the mechanism is information aggregation as opposed to making money, can one develop a parimutuel process that successfully aggregates information? The choice of institutional detail can draw heavily on existing systems, since the field results suggest that they might perform reasonably well. Of course the institution need not mirror any particular system but can be developed, using such theory and intuition that is available, in an attempt to find a process that performs well.

The formal structure of a parimutuel system will make its nature clear. The total tickets sales is shared by the holders of tickets on the winning horse, in proportion of the number of tickets they purchased on this winning horse. Some notation will help make the ideas clear. Let $\mathrm{q}_{\mathrm{ij}}$ be the quantity bet by agent $\mathrm{i}$ on horse $\mathrm{j}$ and let $\mathrm{Q}_{\mathrm{j}}=\Sigma_{\mathrm{i}} \mathrm{q}_{\mathrm{ij}}$ be the total amount bet on horse $\mathrm{j}$ by all agents. $\mathrm{Q}=\Sigma_{\mathrm{j}} \mathrm{Q}_{\mathrm{j}}=\Sigma_{\mathrm{j}} \Sigma_{\mathrm{i}} \mathrm{q}_{\mathrm{ij}}$ is the total amount bet on all horses. $\mathrm{H}$ is the house charge (usually positive and usually a percentage rather than a lump charge as represented here) so the amount available for distribution is $\mathrm{D}=\mathrm{Q}-\mathrm{H}$. The reported odds ${ }^{6}$ for horse $j$ are $\mathrm{O}_{j}=\mathrm{D} / \mathrm{Q}_{\mathrm{j}}$ and the payoff to agent $\mathrm{i}$ is $\mathrm{O}_{j} \mathrm{q}_{i j}$ if horse $\mathrm{j}$ wins. The question that is posed is whether or not the odds $\mathrm{O}_{\mathrm{j}}$ carry accurate information about the probability that horse $\mathrm{j}$ will win and if this information is systematically related to the aggregation of the information about which horse will win that is held in fragmented form by the agents prior to the opening of betting. Suppose for example that different agents have different information about the performance of various horses at recent trials, the health of various horses, recent or likely changes in environmental conditions and how various horses might react, etc. This information, if pooled, could be a very powerful tool in predicting which horse would win a particular race. The question is whether or not parimutuel systems can possess that power. Is the system informationally efficient?

While the general form of parimutuel betting systems is easy to understand there are many operational details about such systems that might influence the accuracy as an information aggregation process. The details of the parimutuel system that we designed are included as Section 2. Section 3 is a discussion of the parameters and the experimental design. Section 4 is a detailed discussion of the experimental procedures. Models that are the best candidates for capturing the behavioral nature of the dynamic and complex processes are reviewed and outlined in Section 5 and an appendix (Appendix D) contains numerical examples. No'general theory of parimutuel systems exists but such systems have similarities with finance. Indeed, the early field studies were motivated by questions about the utility functions that might exist when individuals "invest" in

\footnotetext{
${ }^{6}$ Odds stated at race tracks are usually reported as $D / Q_{j}-1$ to 1 .
} 
parimutuel alternatives. The questions that followed were whether the odds expressed were consistent with efficient markets. The discovery and demonstration by Plott and Sunder (1988) that markets can aggregate diverse information leads naturally to the notion that the same, suitably modified, models and theory that suggested that financial markets can aggregate information could be applied to the behavior of parimutuel systems. Section 6 is a discussion of measures of information aggregation and numerical examples are in an appendix (Appendix D). Section 7 contains the results and Section 8 is a summary of conclusions.

A word about the context of the research is in order. An information aggregation device can fail in several respects. First, the processes used by individuals to process the information to which they are exposed might not conform to Bayes' Law. The literature is filled with observations that are related to the capacity of individuals to operate under Bayes' Law (El Gamal and Grether, 1996). That is, the information aggregation process could fail at the level of individual perceptions. Second, if individual beliefs are consistent with Bayes' Law there might still be problems with their expressions of those beliefs. Their individual decision processes might be flawed, random or impulsive, reflecting lack of experience or lack of understanding about the consequences of their actions or the process in which they are participating (Plott, forthcoming). Third, it might be the case that the mechanism simply does not work as an information aggregation device, even under the best of circumstances. This third possibility is the focus of the research reported here.

The sequential nature of the research and the data gathering process will become evident in the paragraphs that follow. The results are that the parimutuel process works very well indeed as an information aggregation device, given that the private information given to individuals does not rely on their ability to compute according to Bayes' Law. However, the aggregation process is not perfect and the reasons for the limitations are not altogether clear. The bulk of the analysis is a report on some of the patterns that exist in the data.

\section{PARIMUTUEL PROCESS DETAILS}

For ease of exposition the currency used will be called francs. This is the term used in the experiments. As will be discussed later the franc-dollar conversion rate is strictly controlled. While the ordinary language of parimutuels involves horses and winning horses, the language here is the same as was used in all experiments. The concept of a "state" or "market" replaces the concept of a horse and the concept of the "winning market" or the "state that occurred" replaces the concept of a winning horse. Thus agents buy tickets on states as opposed to placing bets on horses.

\section{A. Timing and Mechanism Termination}

Fig.1 An overview of the process is reflected in the timing of the process and is contained in Figure 1. The environments that were studied consist of a series of periods. For each period a state was independently chosen by "nature". The mechanism for choosing the 
state and the natural probabilistic representation of the process was publicly known. After a state was chosen, each agent was given private information about the state. After this information was privately recorded, $\mathrm{K}$ markets were simultaneously and electronically opened, one for each state $\mathrm{s}$. These markets were continuous markets in the sense that at any instant an individual could purchase tickets in any of the markets at a fixed price of one franc per ticket. The individual agent could purchase tickets in lots of one unit or in lots of multiple units and could visit markets for purposes of purchasing as many times as desired, subject to the individual's budget constraint.

All ticket purchases were public information. Each market showed the number of tickets it had left for sale. So, at any instant an individual could compute the number of tickets sold in a market and the associated odds. The process of odds computation was facilitated every minute with a public announcement of the odds that existed at the instant of the announcement. Thus, to a close approximation, individuals were aware of the odds continuously throughout the period when markets were open.

The timing of markets and the process of closing markets were public information. All markets were simultaneously opened. Markets were open without interruption until $T_{\text {min }}$ and the time $\mathrm{T}_{\min }$ was publicly known. All markets were simultaneously closed at some randomly chosen instant in the interval $\left[\mathrm{T}_{\min }, \mathrm{T}_{\max }\right]$. The random process of determining an instant for closing was uniform over the interval and all markets closed without warning.

\section{B. States, Probabilities and Private Information}

$\mathrm{S}=\{1,2, \ldots, \mathrm{K}\}=$ set of $\mathrm{K}$ states.

$P(s)=$ the probability that state $s$ occurs. Both the notation $s$ and the notation $j$ will be used to indicate states, depending upon the context.

$x_{i}=$ the sample of data received by individual $i$ that contains information about which state, $\mathrm{s}$, has occurred.

$\mathrm{n}=$ number of agents.

$\mathrm{x}=\left\{\mathrm{x}_{1}, \mathrm{x}_{2}, \ldots, \mathrm{x}_{\mathrm{n}}\right\}=$ the sample of data received by all individuals.

$\mathrm{P}\left(\mathrm{x}_{\mathrm{i}} \mid \mathrm{s}\right)=$ private information of individual $\mathrm{i}=$ the conditional probability that individual $i$ receives message $x_{i}$ given that the state is $s$.

$P\left(s \mid x_{i}\right)=$ the probability that the state is s given the sample $x_{i}$ computed according to Bayes' Law.

$\mathrm{P}(\mathrm{s} \mid \mathrm{x})=$ the probability that the state is s given the sample $\mathrm{x}$.

The set of states is described by $S=\{1,2, \ldots, K\}$. The prior probability that state $j \in S$ is the state that occurs, is equal to $P(j)$. The individuals, denoted by the set $N=\{1,2, \ldots, n\}$ receive a private information signal $x_{i}$. It contains information about the state that occurs. The sample of all information available is denoted by $x=\left(x_{1}, x_{2}, \ldots, x_{n}\right)$. Private information is drawn from a common knowledge probability function. The conditional probability that better $i$ receives information $x_{i}$, given that state $s$ is the state that occurs, is denoted by $\mathrm{P}\left(\mathrm{x}_{\mathrm{i}} \mid \mathrm{s}\right)$. Given this private information, every individual can revise his prior beliefs 
that state $\mathrm{j} \in \mathrm{S}$ is the state that occurs. This updated belief can be described by the conditional probability $\mathrm{P}\left(\mathrm{j} \mid \mathrm{x}_{\mathrm{i}}\right)$.

\section{Mechanism}

The basic structure of the mechanism is as outlined in the introductory paragraphs. For each state/market individuals can buy tickets at a price of 1 franc each. That is, the tickets for all states/markets are sold at the same price. Tickets are unlimited in supply. Budgets were limited. Each state had a separate market. The market that is associated .with the state that occurred is.the winning market.

$\mathrm{T}_{\min }=$ the minimum time that markets were open for purchases.

$\mathrm{T}_{\max }=$ the maximum time that markets could be open for purchases.

$\mathrm{q}_{\mathrm{ij}}=$ the quantity of tickets that individual i purchases in the state $\mathrm{j}$ market. Since each ticket is priced at 1 it is also the total number of francs spent by individual i in market $j$. $q_{i}=\left(q_{i 1}, q_{i 2}, \ldots, q_{i K}\right)=$ vector with the quantity of tickets i purchases in each market. $\mathrm{Q}_{\mathrm{j}}=\Sigma_{\mathrm{i}} \mathrm{q}_{\mathrm{ij}}=$ the total amount of tickets purchased by all individuals in the market for state $\mathrm{j}$. $\mathrm{Q}=\Sigma_{\mathrm{j}} \mathrm{Q}_{\mathrm{j}}=\Sigma_{\mathrm{j}} \Sigma_{\mathrm{i}} \mathrm{q}_{\mathrm{ij}}$ is the total amount purchased by all individuals in all markets. $\mathrm{H}=$ the house charge/bonus. In parimutuels found in the field this is positive (a charge) but in the mechanism studied here it is negative (a bonus) for reasons that will be explained in sections following.

$\mathrm{D}=\mathrm{Q}-\mathrm{H}$ is the amount of money available for distribution to the winners by the parimutuel mechanism.

$\mathrm{O}_{\mathrm{j}}=\mathrm{D} / \mathrm{Q}_{\mathrm{j}}=$ the payoff odds for state $\mathrm{j}$ given the purchase decisions represented by $\mathrm{Q}$, and $Q_{j}$ and the house charge/bonus $H$. That is, for each ticket that the individual possesses in market $\mathrm{j}$, her or she will receive a payoff of $\mathrm{O}_{\mathrm{j}}$ if state $\mathrm{j}$ occurs.

$P_{j}=Q_{j} / Q=$ the implicit price for state $j$. It is the proportion of tickets sold ("bets placed") for state $\mathrm{j}$.

$\mathrm{W}_{\mathrm{i}}=\left(\mathrm{O}_{\mathrm{j}}-1\right) \mathrm{q}_{\mathrm{ij}}=$ profits (winnings) in francs for individual $\mathrm{i}$ if the state is $\mathrm{j}$.

\section{Individual Utility Functions and Constraints}

$m_{i}=$ the number of units of the medium of exchange (money) held by individual $i$.

$\mathrm{U}^{\mathrm{i}}\left(\mathrm{s}, \mathrm{m}_{\mathrm{i}}\right)=\mathrm{U}^{\mathrm{i}}\left(\mathrm{m}_{\mathrm{i}}\right)=$ the utility function of individual $\mathrm{i}$. It is assumed that individuals care only about monetary holdings and not the particular state. Procedures to induce this property are applied in the environments that are studied.

$\mathrm{M}_{\mathrm{i}}=$ the budget constraint for individual $\mathrm{i}$. The individual can spend no more than $\mathrm{M}_{\mathrm{i}}$ in the parimutuel process. As will be explained in the parameter section each individual had an endowment of cash, $\mathrm{E}_{\mathrm{i}}$, and a loan, $\mathrm{L}_{\mathrm{i}}$, that had to be repaid to the experimenter. $\mathrm{M}_{\mathrm{i}}=\mathrm{E}_{\mathrm{i}}+\mathrm{L}_{\mathrm{i}}$.

$\Sigma_{\mathrm{s}} \mathrm{q}_{\mathrm{is}} \leq \mathrm{M}_{\mathrm{i}}$ the spending of individual $\mathrm{i}$ in all markets is limited by the agent's budget constraint.

After market closure, better i receives a profit $W_{i}=q_{i s} O_{s}-\sum_{j} q_{i j}+E_{i}$ if market $s$ represents the chosen state. 


\section{PARAMETERS AND EXPERIMENTAL DESIGN}

Tbl.1 The choice of parameters and the experimental design, summarized in Table 1, reflects the design and exploratory objectives of the research. In total, four different sets of parameters were used in seven associated experiments including the "pilot". In Table 1 the seven experimental sessions are indexed according to the date of the experiment beginning with the pilot experiment 111995 . The state, and the information held by individual agents, could possibly differ each period, so each period confronted the parimutuel system with a possibly different information aggregation problem. The combination of the six experiments with the parimutuel process provided an opportunity to gather much data. In total the decisions of 85 subjects in 108 periods (excluding practice periods) were observed and studied.

The capacity of the parimutuel system to aggregate information was completely unknown at the time of the design, and models that might have been applied to anticipate what would happen are substantially incomplete. Thus, the data gathering started with a single pilot experiment in a very simple, three state environment that is known to cause aggregation problems in similar informational environments in the context of asset markets (Plott and Sunder, 1988). The experiments that followed the pilot were designed conditional on what was observed in the pilot and these subsequent experiments began to constitute a type of "stress test" of the mechanism that increased in difficulty as more information about the behavior of the process was acquired. For example, the last periods of the early experiments used the parameters that were planned for possible use in the next experiment. As can be seen in the table, the parameters begin with what might be thought of as the "easiest" of the cases studied, and then, as successful aggregation is observed, subsequent parameter choices become "harder". The easiest conditions are called the NOT SETS condition and the harder conditions are called the Probabilistic Information Condition (PIC).

\section{A. States and Information}

The pilot experiment (111995) had three states for the initial three periods (periods $0,1,2$ ) and six states for the other periods. Had information aggregation not been observed in the first three periods, the design called for other periods to have three states. In this three state environment, the aggregation was clear so the subsequent periods involved six states The results of the three state periods are not used for further analysis.

States were given names. In the three-state environment the states were names SX, SY, and SZ. In the six-state environment the names of states also consisted of two letters. The first letter was one of $\{S, T\}$ and the second letter was one of $\{X, Y, Z\}$.

In all cases the state was drawn with a uniform distribution over states. Two different private information conditions were studied. In the NOT SETS condition, agents were 
individually given information about states that did NOT occur. The privately held information was such that the state that occurred could be deduced with certainty, from pooled private information. Thus, in the NOT SETS condition the "system" knew with certainty the state that occurred, but no individual knew the state with certainty.

Specifically, in the NOT SETS condition for the six-state cases, (experiment 111995 , periods 3 thru 8; experiments 112995 and 113095 , periods 0 thru 16), each period the agents were randomly partitioned into three equal-sized groups. One group received information that allowed it to eliminate one of the letters $\mathrm{S}$ or $\mathrm{T}$, depending on the state that occurred. The other two groups each received information that allowed them to eliminate one of the letters $\mathrm{X}, \mathrm{Y}$, or Z. Suppose for example that the state that occurred was SY. Then one-third of the agents knew NOT T, one third knew NOT X and one third knew NOT Z. Collectively the agents knew the state that occurred, but no one knew the state with certainty. ${ }^{7}$

In the Probabilistic Information Condition (PIC), experiments 112995 and 113095 (periods 17 and 18), experiments 121595, 061896A, 061896B, and 061996 (periods 0 thru 16), private information was given as a sample and a computed conditional probability of the state given the sample. The sample consisted of three independent draws with replacement, taken from an urn with the probability of the correct state equal to one third (five fifteenths) and the probability of each of the five other states equal to two fifteenths. Both the actual draws and the conditional probability (calculated by Bayes' Law) that each state would be the state that occurred, were given as private information.

Formally stated, with the Probabilistic Information Condition (PIC), each agent, i, saw a sample of three draws from a multinomial distribution. For ease of exposition, let $\mathrm{x}_{\mathrm{ij}}$ be the number of times the state $\mathrm{j}$ occurred in i's sample, so the sample seen by any agent $\mathrm{i}$ can be represented by the vector $x_{i}=\left(x_{i 1}, x_{i 2}, x_{i 3}, x_{i 4}, x_{i 5}, x_{i 6}\right)$, where $x_{i j} \in\{0,1,2,3\}$ and $\sum_{j=1}^{6} x_{i j}=3$. That is, given that the state that occurs is $s$, the information $x_{i}$ is drawn from the multinomial distribution:

(1) $\mathrm{P}\left(\mathrm{x}_{\mathrm{i}} \mid \mathrm{s}\right)=\left(\frac{3 !}{x_{i 1} ! x_{i 2} ! x_{i 3} ! x_{i 4} ! x_{i 5} ! x_{i 6} !}\right) p_{1, s}^{x_{i 1}} p_{2 s}^{x_{i 2}} p_{3 s}^{x_{i s}} p_{4 s}^{x_{i 4}} p_{5 s}^{x_{i 5}} p_{6 s}^{x_{i 6}}$.

where $\mathrm{p}_{\mathrm{s}^{\prime} \mathrm{s}}=$ the probability that a single draw will be the state $\mathrm{s}^{\prime}$ when the actual state that occurs is s can be written as

$p_{s^{\prime} s}=\left\{\begin{array}{cc}1 / 3 & \text { if } s^{\prime}=s \\ 2 / 15 & \text { if } s^{\prime} \neq s\end{array}\right.$

\footnotetext{
${ }^{7}$ The "NOT SETS" information in the three-states periods (111995), periods 0 thru 2, was similar. In the three-state case, the state was one of the letters $\mathrm{X}, \mathrm{Y}$, or $\mathrm{Z}$. If, for example the state was $\mathrm{X}$ then a randomly chosen half of the agents received the information NOT $Y$ and the other half received the information NOT $Z$. Thus, collectively the state was known but no individual knew the state.
} 
In addition to the sample, the individual was given the probability, computed by application of Bayes' Law, of each state being the state that occurred given the particular sample that the individual drew. That is, for each state s, each individual agent was given the number that resulted from the evaluation of the function

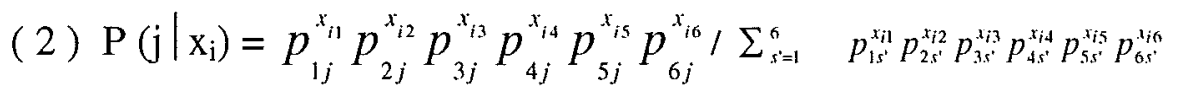

Consider an example of the Probabilistic Information Condition (PIC). Suppose the resulting state SX was the actual state and that the sample drawn by agent i was $\{T Y, S X$, SZ $\}$. The individual would then be given the sample $\{$ SX, SY, SZ, TX, TY, TZ $\}=\{1,0$, $1,0,1,0\}$ and the vector of posterior probabilities $\{0.238 ; 0.095 ; 0.238 ; 0.095 ; 0.238$; $0.095\}$ indicating the probability of each of the six states given the agent's private information and the prior probabilities of the states.

The actual computations of Bayes' Law were given in order to control for possible bias and errors at the first instance of the information aggregation process. The questions posed by the research focused primarily on the ability of the process to aggregate information held at the individual level. If the experiment did not effectively control the information at the individual level then a problem would remain to determine if the errors of the aggregation mechanism were due to contamination (from the point of view of modeling) at the initial step of the process. While this procedure does not completely guarantee the elimination of biases, it reflects an attempt to reduce them.

All parameters were chosen after a review of the consequences for the aggregate information that the mechanism would be processing. For example, in the PIC a sample of three under the conditional probabilities (1/3 for the state that occurs and 2/15 for each of the five others) might seem to be very little at the individual level of analysis, but the distribution formed by the pooling of all agents' information, when there are from ten to fifteen individuals, can be very peaked at one state. In other words, the choice of parameters was such as to make the variance high at the individual level, so the individual had much to learn from the process, and yet make the variance small at the aggregate level in order to facilitate clear predictions. Of course, depending upon the samples drawn, it is always possible that in some periods more than one state has a high likelihood.

\section{B. Endowments, Loans and $\mathrm{H}$.}

The choice of endowments and loans was based on incentives and common experimental practices. Each period, each individual was given an endowment $\mathrm{E}$ of one hundred units of house money which translated into one dollar. Recall that it is possible for individuals to lose money in a parimutuel process and this endowment provided a base that would help prevent bankruptcies. The agent was paid the endowment of one dollar whether or not he or she participated. The loan L of three hundred units money gave agents an 
opportunity to buy beyond their endowment, while placing an overall budget constraint on their exposure to bankruptcy. The total budget $\mathrm{M}$ is equal to the sum of $\mathrm{E}$ and $\mathrm{L}$. The individuals could lose (a real loss) no more than $\mathrm{L}-\mathrm{E}$ in a single period or the individual could güarantee an income of $\mathrm{E}$ per period by doing nothing.

The house charge/bonus, $\mathrm{H}$, was negative. That is, $\mathrm{H}$ was a bonus paid by the house $(\$ 12$, $\$ 15$, or $\$ 10$, depending upon the number of subjects) rather than a "tax" so, unlike the examples of parimutuels found in the field, which operate for profit, the mechanism we created lost money for the house. This transformed the lotteries from ones that had negative expectation of earnings to lotteries that had positive expectation and thus gave all individuals who might be risk averse some incentive to invest in tickets. If the expectation had been negative due to a house "cut", then risk-averse individuals with private information may have had no incentive to participate. As a result their private information would never be reflected in the behavior of the system.

\section{Time, Timing and Mechanism Termination}

The importance of the termination of a mechanism is well known. Incentives to wait in order to get information while giving none, frequently exist in mechanisms where conflict of interest is present. A random stopping rule was employed to help overcome the problem. Its effectiveness has been demonstrated in experiments. In many senses, due to the timing and processing of bets ( the lines of people at betting windows, etc.), random stopping rules might effectively exist in parimutuels found in the field.

In all periods of all experiments the markets operated for a maximum of five minutes $\left(\mathrm{T}_{\max }=5\right)$. The minimum length of time that markets were open, $\mathrm{T}_{\min }$, differed across experiments. In the NOT SETS condition the minimum length of time that the markets were open, was four minutes $\left(\mathrm{T}_{\min }=4\right)$. In the first set of experiments under PIC the markets were open for at least four minutes $\left(\mathrm{T}_{\min }=4\right)$. In the second set of experiments under PIC this minimum possible was reduced to two minutes $\left(\mathrm{T}_{\min }=2\right)$. The former condition is called the PIC-4, the latter is PIC-2. The reason for decreasing this minimum time was due to the imperfect aggregation property observed in the PIC-4 condition, as will be shown later. In the PIC-4 design, the one minute period between minimum and maximum time appeared to be short relative to the pace of market activity. On average this period lasts only half a minute. It was thought that early terminations might have prevented aggregation. Thus under PIC the minimum length of time became an experimental condition.

\section{PROCEDURES}




\section{A. Subjects and Recruiting}

Subjects were Caltech undergraduates and graduates. Most of the subjects were familiar with the computer technology as a result of previous market experiments, but many were completely inexperienced with the actual experiment. Recruiting was done through internet e-mail. Subjects in 112995 were completely inexperienced. The second experiment, 112995, used a mix of experienced and inexperienced agents as did experiment 113095. The fourth experiment, 121595, used all inexperienced agents. Experiment $061896 \mathrm{~A}$ and $061896 \mathrm{~B}$ contained mostly inexperienced subjects. Finally, the subjects in 061996 were recruited from experiments $061896 \mathrm{~A}$ and $061896 \mathrm{~B}$. Thus, only in 061996 all subjects were experienced with the actual experiment. The number of agents varied across experiments according to the availability of subjects.

\section{B. Instructions, Chalkboard and Training}

Subjects were given the written instructions contained in Appendix A. These instructions were read to the subject with the aid of the presentations on the chalkboard. After the instructions were read and questions were answered the markets were open for a period 0 which was only a practice session in which no real money was involved. This practice session used all of the methods of purchasing, announcements, etc. of the actual parimutuel that was employed, except for the fact that no real payments were involved.

\section{Technology: Information}

Because of the need to distribute private information with the appropriately calculated posterior probabilities the events and samples were pre-drawn. This fact of pre-drawn states and samples was public information. Subjects were told that the states were drawn using a random number table that could be inspected by anyone after the experiment. None of the subjects asked to inspect the table.

Private information for the appropriate number of agents was written on slips of paper and put into a box each period. The experimenter walked around the room and allowed each subject to draw a slip, without looking, from the box. The form of the slip is in Appendix B. With NOT SETS conditions, this slip indicated a state which did not occur. In the Probabilistic Information Condition, it contained for each state the number of times the state was drawn in a sample from the urn and also the posterior probability of each state being the state that occurred given the sample. The subjects recorded that information in the appropriate place on their record sheet, as shown in the Appendix . These procedures were used for all periods of all experiments.

D. Technology: Markets and Feedback Information 
The software generally available for the multiple unit double auction (MUDA) was adapted to become a parimutuel system. A separate market was opened for each state and the experimenter offered a fixed quantity of "tickets" for sale at 1 franc each. The quantity for sale, which exceeded the maximum that could possibly be purchased by the group, was displayed on each subject's computer screen. Individual agents, buyers, were free to toggle among markets and make purchases as they wished in real time. As agents purchased tickets, the quantity offered for sale was reduced by the amount of the sale, so the difference between the initial quantity offered and the post-purchase quantity remaining at the moment was a measure of the total number of tickets purchased. Thus agents had instantaneous access to the number of tickets purchased and thus had instantaneous access to the odds.

Periodically the experimenter announced the odds that existed at the moment using an overhead projector. This calculation of odds required the manual entry of ticket sales from all markets into a computer attached to the overhead. The resulting computation and projection by overhead required a few seconds, so odds were precisely computed and made available only with some small delays.

The times $\mathrm{T}_{\min }$ and $\mathrm{T}_{\max }$ were announced by the experimenter in advance. When the time $T_{\min }$ passed the experimenter made a second announcement so subjects were aware that the end would be randomly determined from then on. A clock on each agent's computer gave the agent continuous access to time. The period was closed randomly without warning. The experimenter had randomly chosen a second at which the experiment should stop. When this second arrived the experimenter pressed a computer key that closed the period instantaneously.

When the period ended the state was announced and written on the chalkboard. The final odds paid on the state were announced. Each agent calculated earnings (positive or negative) for the period. At the beginning of the next period, information for the next period was drawn from the box by each agent and markets were opened for the purchase of tickets.

\section{MODELS}

The fundamental questions posed by the research are: does information aggregation take place and if so, what is the process through which it happens. In order to answer such questions, several different concepts are needed. First, in Section A, the information possessed by individuals and by the market as a whole are described. Second, in order to address the nature of aggregation, several different classes of behavioral models are reviewed in Sections B through D. These models are based on different principles of individual perceptions and behavior, ranging from theories that have individuals behaving myopically, having no response to the presence of others, to theories that have individuals nearly clairvoyant about what others will do. Some of the predictions of these models are in Table 2. Appendix D contains a numerical example. 


\section{A. Information}

Two concepts of information are used in the development of all of the models and measurement methods. The first measure is related to the information given to individuals and is a parameter of many of the models.

(i) Private Information. As was discussed above, the nature of the private information differed across experiments. In the NOT SETS condition the private information was $P\left(j \mid x_{i}\right)=1 / K_{i}$ where $K_{i}$ is the number of states not eliminated by i's private information and $\mathrm{j}$ was not eliminated. In the Probabilistic Information Condition (PIC) the information was given as a draw from an urn conditional upon the state and in terms of the probabilities given in equation (2) in Section 3 above.

(ii) Aggregate Information Available (AIA). This measure is obtained by the pooling of all information given to individuals. It is the best information that exists in the system concerning the state. It can be represented by the conditional probability $P(j \mid x)$. In the NOT SETS condition, the AIA was a signal that correctly pointed to the state that occurred. In the PIC, the fact of independence in the draws could create, by aggregation, a strong signal that put most probability mass on the state that occurred. The aggregated posterior probabilities can be computed according to the formula ( 3 ), where the number of times that state $\mathrm{j}$ appears across all $\mathrm{n}$ individual agents' draws is

$\mathrm{x}^{\mathrm{j}}=\sum_{i=1}^{n} x_{i j}, \mathrm{j}=1,2, \ldots, 6$

and, accordingly, the posterior probability that $\mathrm{j}$ is the state that occurs, given the aggregate of information distributed to all individuals is:

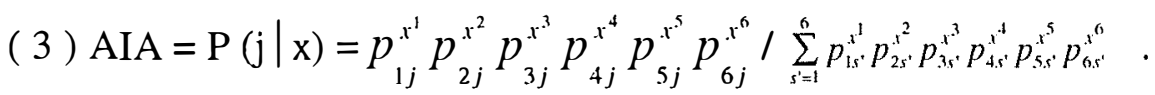

\section{B. Private Information Models}

The models in the section above are related to concepts of information. The discussion now turns to behavior. Two models considered tend to rest on the principles of optimization at the level of individual choice. However, the information used in individual choices does not go beyond the private information that the individual has. The models rely on the principle that individuals learn nothing about the state that occurs from the actions of other individuals. The difference between the two models is the response to market prices.

Decision Theory Private Information (DTPI). The individual chooses the market that yields the highest expected returns, given private information and given a belief that the return is the same for all markets. It is as if the individual must decide how to invest before observing any implicit prices. The model allows neither learning nor strategic behavior. 
Competitive Equilibrium Private Information (CEPI). The competitive equilibrium is calculated according to the principle that all agents take market prices as constants. Market price in the context of the parimutuel betting system is taken as the odds. The prices are those that equate quantity of tickets supplied with the quantity of tickets demanded. In the case of CEPI the information on which individual demand is based is the private information. The optimization problem is that the agent maximize conditional expected utility, given private information. That is, from an agent perspective, the decision problem this agent has to solve is to maximize expected profit subject to constraint, and can be written as,

$$
\begin{aligned}
& \max _{q_{i}}\left\{\mathrm{E}\left[q_{i s} O_{s}-\sum_{j=1}^{K} q_{i}+\mathrm{E}_{\mathrm{i}} \mid x_{i}\right]\right\} \\
& \text { s.t. } \sum_{j=1}^{K} q_{i j} \leq M .
\end{aligned}
$$

In the NOT SETS condition, in which the private information consists of a set of states that can be eliminated, this maximization problem reduces to

$$
\begin{aligned}
& \max _{q_{i}}\left\{\sum_{j \in X i} q_{i j}\left(\frac{O_{j}}{K_{i}}-1\right)+E_{i}\right\} \\
& \text { s.t. } \sum_{j=1}^{K} q_{i j} \leq M .
\end{aligned}
$$

where $X_{i}=\{j \in S$ I in state $j$ is not eliminated by the private information i received $\}$ and $K_{i}$ is the number of states this set (the number of those that are not eliminated by i's private information). The solution to this problem is an individual demand correspondence, as a function of the odds $\mathrm{O}=\left(\mathrm{O}_{1}, \ldots, \mathrm{O}_{\mathrm{K}}\right)$, .

$$
q_{i j}(O)=\left\{\begin{array}{cc}
M & \text { if }\left\{\frac{O_{j}}{K_{i}}>1 \wedge O_{j}>O_{j^{\prime}}, \forall j^{\prime} \in X_{i}\right\} \\
{[0, M]} & \text { if }\left\{\frac{O_{j}}{K_{i}} \geq 1 \wedge O_{j} \geq O_{j^{\prime}}, \forall j^{\prime} \in X_{i}\right\} \\
0 & \text { otherwise }
\end{array}\right.
$$

for $\mathrm{j} \in \mathrm{X}_{\mathrm{i}}$, and,

$$
q_{i j}(O)=0
$$

for $\mathrm{j} \notin \mathrm{X}_{\mathrm{i}}$, and additionally, 


$$
\begin{array}{lc}
\sum_{j=1}^{K} q_{i j}(O)=M & \exists j \in X_{i}, \frac{O_{j}}{K_{i}}>1, \\
\sum_{j=1}^{K} q_{i j}(O) \leq M & \text { otherwise }
\end{array}
$$

In words, this correspondence can be described as putting one's money at a noteliminated market with the highest odds. Additionally, these odds have to be large enough with respect to i's private posterior probabilities. The Walrasian equilibrium condition implies that,

$$
O_{j}=\frac{\sum_{i=1}^{n} \sum_{k=1}^{K} q_{i k}(O)-H}{\sum_{i=1}^{n} q_{i j}(O)}, j=1, \ldots, K
$$

Proposition. For the NOT SETS condition it can be shown that for the CEPI model:

(i) the implicit prices satisfy,

$$
P=\left(P_{1}, P_{2}, \ldots, P_{K}\right)=\left(\frac{1}{K}, \frac{1}{K}, \ldots, \frac{1}{K}\right) ;
$$

(ii) the total volume is equal to the sum of the budgets;

(iii) the distribution of profits depends on the distribution of tickets in equilibrium.

Proof. Existence and uniqueness can be found in Eisenberg and Gale (1959). Hence, it suffices to check whether the given odds vector (the implicit price vector) satisfies the equilibrium conditions. For this odds (price) vector, all individuals are indifferent between tickets at markets which are not eliminated by their private information. Consequently, it is easy to construct a vector of allocations that satisfy the Walrasian equilibrium condition and distributes tickets to individuals at markets that are not eliminated by their private information.

The analysis above is restricted to the case in which private information is of the special form in which some subset of states can be eliminated with certainty. For the PIC the Eisenberg and Gale analysis applies to establish existence. So, existence is not a problem but closed form solutions are not generally possible in the PIC. However, it is possible to compute the equilibrium prices by using numerical fixed-point algorithms (Van der Laan and Seelen, 1984). For the parameters of the experiment such calculations were made and are presented as part of the results.

C. Models with Updated Beliefs 
The second class of models relies on a principle that behavior is based on beliefs that are consistent with experience. The first model is not game theoretic in nature. The second model involves deeper postulates about the nature of the process through which information about others is transmitted.

Competitive Equilibrium Rational Expectations (CERE). This model is used as a benchmark as opposed to adding postulates about individual behavior. In this model prices, (odds), are taken as constants from the point of view of the individual agent. The postulate at the foundation of the model is that the prices are perfectly revealing and are thus distributed according to AIA. That is, according to this model, the implicit prices will seek an equilibrium in which all available information has been integrated into the prices.

Existence of such a price vector is not a problem. Since the expected values are constant, in a risk neutral world, all agents exhaust their budgets.' The expected value of all markets would be the same given the equilibrium odds so individuals would be indifferent among the markets. Thus, the model makes no unique predictions about quantities held in relation to the private information as long as the allocation satisfies the system constraints. All agents should be equally profitable.

The common drawback of market models like the competitive equilibrium private information model and the rational expectations model lies in the fact that it postulates the assumption that agents consider the price as a fixed quantity, independent of one's actions. This assumption is questionable, as it does not explain the origin of the price, and furthermore, it is difficult to maintain in markets with a small number of traders. Therefore the assumption that the price is fixed is discarded and the following model is introduced.

Bayesian Games. Full game theoretic models of the information and strategic possibilities are not fully developed. In this subsection the process is described as a Bayesian game, in which every agent simultaneously has to decide how many tickets he would like to purchase at each market. That is, a strategy profile $\mathrm{q}^{*}=\left(\mathrm{q}_{1}{ }^{*}, \mathrm{q}_{2}{ }^{*}, \ldots, \mathrm{q}_{\mathrm{n}}{ }^{*}\right)$ is a Bayesian Nash equilibrium if every risk-neutral agent with private information $x_{i}$ maximizes his expected profit,

$$
q_{i}^{*} \in \underset{q_{i}}{\arg \max } \mathrm{E}\left[q_{i s} \frac{\sum_{k=1}^{n} \sum_{j=1}^{K} q_{k j}-H}{\sum_{k=1}^{n} q_{k s}}-\sum_{j=1}^{K} q_{i j}+E \mid q_{-i}=q_{-i}^{*}, \mathrm{x}_{j}\right]
$$

and satisfies his budget constraint

$$
\sum_{j=1}^{K} q_{i j}^{*} \leq M
$$


In the NOT SETS condition, a Bayesian Nash equilibrium exists in which all agents will follow what will be called the proportional allocation strategy. That is, they will equally divide their budget over the markets that are not excluded by their private information., i.e.

$$
q_{i j}=\frac{M}{K_{i}}
$$

for $\mathrm{j} \in \mathrm{X}_{\mathrm{i}}$, and,

$$
q_{i j}=0
$$

for $\mathrm{j} \notin \mathrm{X}_{\mathrm{i}}$. This result can easily be extended to a multi-stage game, where at each stage agents can decide how many tickets they would like to purchase at the markets, and each agent is informed about all the tickets sales at the end of each stage. In this multi-stage game, an equilibrium strategy is one in which each agent purchases tickets at the last stage, identical to the strategy described in the one-stage game.

Agents will divide their budget across states in proportion to the relative probability of the state in their private information. The normalized price for each state $\mathrm{j}$ is given by $1 / n \sum_{i=1}^{n} P\left(j \mid x_{i}\right)$. The volume is equal to the sum of the budgets. The profits are equally distributed in the situation with three markets, but show heterogeneity in the 6 markets environment. Agents who can exclude more states by their information, possess an informational advantage that results in higher profits.

In Probabilistic Information Conditions (PIC), we did not succeed in finding the equilibria in this game.

\section{Herding Behavior: (Excessive Use of Market Data)}

The class consists of a single model that is based on the principle that individuals simply ignore their own information and mimic others completely. The idea is more qualitative than the models considered above. While within the finance literature ${ }^{8}$, different kinds of models are used to explain herding behavior, the basic idea here is that agents base their actions solely on the information the market reveals, as the signal provided by the market is stronger than their private information. Related to a parimutuel setting, in which there is only one market that pays, a prediction of this model is that (a subset of) traders "jump" too impulsively at a market. Broadly speaking, the herding model would predict lots of action in one particular market, i.e. the implicit price of one of the markets is fairly high. Which market receives all of the action depends on the initial actions taken in the markets and may be unrelated to the actual state that has occurred or the privately held information about states.

${ }^{8}$ see e.g. Scharfstein and Stein (1990), Welch (1992). 


\section{BASELINE MEASURES OF INFORMATION AGGREGATION}

The major variables of interest are the implicit prices and the information that they contain. In this section three questions about information measurement are answered. How is the level of information in the prices measured? How does one compare levels of information in different patterns of prices? What baselines are used as the background against which information aggregation measurements can be made? Appendix D contains numerical examples of the concepts used in this section and in the section above.

In the finance literature the classical methodology of assessing information aggregation relies on concepts of market efficiency. The question is whether or not markets are "efficient" in the incorporation of information in the sense that no one is able to make a profit from information contained in prices. Two related concepts of efficiency have been posed.

Weak statistical efficiency: This form of efficiency demands that there are no obvious trading rules that significantly outperform the average. Operationally speaking, the parimutuel market is weakly efficient if there are no obvious filter rules that make significant returns.

Strong statistical efficiency: The market is strongly efficient if insiders do not make significantly higher returns than noninsiders.

Direct measurement of information aggregation is generally not possible in the field of finance because the information held privately is not observable. This can lead to misinterpretations of the results. For example, Plott and Sunder (1988) found that a market can have the property of weak statistical efficiency even though the information that exists to be aggregated in the market is not aggregated into price at all.

Since experimental methods have been utilized in this study, better measurement methods can be employed. Measures of the degree of aggregation involve comparisons of distributions. In the evaluation of information aggregation it will be necessary to adopt conventions for determining when one distribution, $\mathrm{p}$, is close in information content to another distribution, q. Two different conventions present themselves. If the discrete distributions are described by their probability density functions $\left\{p_{i}\right\}_{i=1 . . K}$ and $\left\{q_{i}\right\}_{i=1 . . K}$ respectively, then the measure proposed by Würtz $(1996)^{9}$ can be written as

$$
W(\mathrm{p}, \mathrm{q})=0.5 \sum_{i=1}^{K}\left|p_{i}-q_{i}\right|
$$

whereas the Kullback-Leibler measure (Kullback and Leibler, 1952) is described by

\footnotetext{
${ }^{9}$ This measure is proportional to the average absolute prediction error, as used by Berg, Forsythe and Rietz (1995) to examine the efficiency of their political stock market.
} 


$$
K(\mathrm{p}, \mathrm{q})=\sum_{i=1}^{K} \log \left(p_{i} / q_{i}\right) p_{i}
$$

The next important ingredient of information aggregation measurement is the baseline. What does it mean for "no aggregation" to have occurred? Against what base do we want aggregation to be measured? Four different measurements are listed. Three of these are directly related to the models described in the previous section. The fourth is added as a type of boundary for the support of the private information. Since each of these measures can represent a probability distribution, they are called "opinions". In the measurements of information aggregation the q-distribution will be the Aggregate Information Available (AIA), used as a benchmark against which the p-distribution, the implicit prices, and the baselines given below, will be compared to determine the "distance" of the chosen baseline from "perfect" aggregation.

\section{(i). Decision Theory Private Information (DTPI) Opinion}

On the one hand, this opinion would be obtained if all subjects answered the question "which state is most likely to occur" and the average (mean) of those opinions was calculated. On the other hand it is the Decision Theory Private Information model equilibrium price pattern. Since it reflects a type of myopic decision making, it could be viewed as a base against which aggregation could be measured.

\section{(ii). The Competitive Equilibrium Private Information (CEPI) Opinion}

If individuals make decisions only on their own private information and if the markets work competitively, then this is the price pattern that would emerge. The competitive model does force some type of merging of information, as reflected in price. However, since it involves no explicit information aggregation as part of the behavior of the model, it is an alternative baseline.

(iii). Average Opinion.

If subjects truthfully reveal their private posterior distribution, this opinion would be reached by averaging those private opinions. If odds reflect this type of aggregation then prices are distributed according to the average information that is held privately. That is, the normalized price for each state $\mathrm{j}$ is given by $1 / \mathrm{n} \sum_{i=1}^{n} \mathrm{P}\left(\mathrm{j} \mid \mathrm{x}_{\mathrm{i}}\right)$. This is the price pattern that results from the proportional allocation predicted by the Bayesian game in the NOT SETS condition. Since it is a natural measure it will be used in the PIC as well.

\section{(iv). Best Opinion.}

This opinion is constructed by taking the posterior distribution of the best informed individual, i.e. the individual whose private posterior distribution is closest to the aggregate information available. In a sense, it is part of the support for the distributions of private information. It represents the distribution that is "closest" to the truth that might be the result of aggregation. Information that is better than this measure has unambiguously been aggregated. 


\section{RESULTS}

Fig.2-A,B,

Fig.3-A,B,

Before the results on aggregate level are described, we think it might be useful to consider the results of a few typical periods. Figure 2-A,B and Figure 3-A,B provide a qualitative representation of the data. Shown in each panel A is the total amount of money bet in the six markets. These lines are represented as cumulations of spending in the sense that if line $\mathrm{x}$ is above line $\mathrm{y}$, the distance from line $\mathrm{x}$ to line $\mathrm{y}$ is the investment in market $\mathrm{x}$. The $B$ panels are perhaps more informative because these show the bets in each market as a percentage of all bets in all markets, the implicit prices that are discovered in the markets. The vertical line seen at $4 / 5$ the distance of the time scale represents the minimum time for which the markets are open, after which the markets all close at a randomly chosen time within the next minute.

Figure 2-A,B shows the time-series of ticket purchases of market period 11 in experiment 112995, whereas Figure 3-A,B gives similar results for the same period in experiment 113095. Both of these experiments have a NOT SETS information structure. In the 112995 experiment, state TY was the state that occurred, whereas in the 113095 experiment, the state SZ occurred.

The A-panels tell us that absolute volume was relatively small during the minutes before the time $\mathrm{T}_{\min }$. In the last seconds before this point in time, market volume suddenly started rising. Most of the ticket sales were realized in this small time interval. As can be seen in the B-panels, early in the market the relative betting wandered across all markets until time was near the vertical line. As the minimum time approached the betting became heavier in a few markets and then, one market began to emerge as the one that is clearly attracting the most bets. In period 11 of experiment 112995 (Figure 2-B), the market that emerged with the highest price was indeed the winning market. The prices of the other states fell. Thus, for this period the state that occurred was the market with the highest price and the winner was thereby revealed by price. Of course, if the prices were perfectly revealing of the information then the prices of each state would be equal to the probability that the state occurs, according to the aggregated private information. The price of the winning market was short of the actual probability (probability $=1$ ) and the prices of the other states were "close" but not exactly equal to zero. In Figure 2-A it is observed that in this period ticket sales hardly occurred after the fast emergence in one market, or when the volume is close to the maximum level of spending.

In Figure 3-B, period 11 of experiment 113095, a different story can be told. In this period one observes a so-called bubble in the sense that the market that emerges is not associated with the state that occurs. Whereas SZ was the state that occurs, the emerging market was market SX. However, contrary to the previous figure, in this period a lot of action was still going on after the emergence. Traders who received an information slip that told them to exclude market $X$ from the possible winners, were fully aware of the fact that a bubble was occurring. These subjects knew that the tickets sales spent in the SX market would be lost to those that have invested in the right market. The adjustment patterns initiated by these subjects can explain the drop in the price of SX just after $T_{\min }$. 
Now, a more formal discussion of the results is presented. The discussion is partitioned into several subsections, in which the questions formulated in the previous sections will be explored.

\section{A. Statistical Efficiency Measures}

The weakest form of efficiency demands that there are no obvious trading rules with returns that significantly outperform average returns. Following previous studies in parimutuel betting, the trading rule examined is. one which uses the ranking of the horses by the market, e.g. a rule which allocates one's budget to the market with the highest implicit price.

RESULT 1. The parimutuel markets exhibit weak statistical efficiency under both sets of information conditions, NOT SETS and PIC.

SUPPORT. A ticket's price in a market is the implicit price. For each period of each experiment, markets are ranked by the implicit prices that existed at the close of the period. The market with the highest implicit price is called the $1 \mathrm{st}$, the market with the next highest implicit price is called the 2 nd, and so on. The average implicit price is computed for each rank and the relative frequency of winning is computed for each rank. Table 3 contains the computations. That is, the average implicit price of the 1 st, computed across all periods for the NOT SETS experiments, is 0.744 and the relative frequency with which the 1st actually won in these experiments was 0.763 . In Table 4 the numbers are computed for the probabilistic cases. In the PIC the implicit price for the $1 \mathrm{st}$ is, on average, 0.536 and the 1 st wins 0.588 percent of the periods, etc.

In a weakly efficient market, implicit prices and expected returns ${ }^{10}$ should be equal. The parimutuel markets exhibit weak statistical efficiency for both the NOT SETS and the PIC. ${ }^{11}$. For both sets of data a strong relationship exists between the average implicit prices given the rank of a market and the probability of winning. In empirical terms, these results suggest that all information has been aggregated in implicit prices.

Weak statistical efficiency means that "outsiders", those who have only price information, cannot make extraordinary profits. Having established that from an outsider point of view it is not possible to make significantly higher returns, the question remains whether this is possible for an insider. Insiders are defined as those agents who receive

\footnotetext{
${ }^{10}$ A ticket's return in a market, $\mathrm{j}$ is related to the objective winning probability of the market $\mathrm{j}$. This probability is defined to be the proportion of times the market is the winning market, as the game is repeated an infinitely large number of times. If there are finite number of games played by the subjects, this probability can be estimated by the average number of periods that market $\mathrm{j}$ is the winning market.

${ }^{11}$ Consider a chi-square test of the form $\left.\sum_{j=1}^{6}\left(W M_{j}-T P_{j}\right)^{2} / T P_{j}\right) . \mathrm{WM}_{\mathrm{j}}$ is the number of periods that market $\mathrm{j}$ is the winning market; $\mathrm{T}$ is the number of periods (observations); $\mathrm{P}_{\mathrm{j}}$ is the average implicit price for market $j$. For $\chi_{j-1}^{2}$, the statistic is 1.084 for the NOT SETS and 2.176 for the probabilistic. In both cases weak efficiency of the markets cannot be rejected. Additionally, the results of a t-test (Ali, 1977) do not reject weak statistical efficiency, as can be read in Table 3 and Table 4.
} 
information that assigns the highest posterior probability to the event that the state that occurs is the true state (which is unknown for the insider, but known to the experimenter). Strong statistical efficiency means that insiders cannot make significantly higher returns than outsiders or cannot make significantly higher returns than other insiders who might have different information.

RESULT 2. Strong statistical efficiency means that there should be no relationship between private information and profits. Strong statistical efficiency is present in the NOT SETS conditions but it is not present in the PIC.

SUPPORT. The relation between profits, $\mathrm{W}_{\mathrm{i}}$, and inside information, $\mathrm{P}\left(\mathrm{s}^{-} \mid \mathrm{x}_{\mathrm{i}}\right)$, can be examined by the linear model,

$$
\mathrm{W}_{\mathrm{i}}=\alpha_{\mathrm{i}}+\beta \mathrm{P}\left(\mathrm{s} \mid \mathrm{x}_{\mathrm{i}}\right)+\varepsilon_{\mathrm{i}}
$$

The error-term $\varepsilon_{\mathrm{i}}$ is normally distributed with mean 0 and variance $\sigma^{2}$, and all errors are independent. The constant $\alpha_{i}$ is individual-specific to allow for individual differences among betters. ${ }^{12}$ Estimation results can be read in Table 5. In both information structures, it can be observed from the estimated coefficient, $\beta$, that the relationship between the quality of information and profits is positive. In the NOT SETS condition, this relationship is not statistically significantly different from zero at a $5 \%$ level, whereas it is significantly different from zero in the PIC. This leads to the conclusion that in the PIC, strong efficiency is rejected, whereas in the NOT SETS condition even strong efficiency can be upheld. ${ }^{13}$

The second result suggests that decisions about which market to buy have a substantial variance across individuals in the PIC. Such differences in investments can be interpreted as differences in individual opinions about expected values, possibly reflecting some incompleteness in information aggregation. If the information is perfectly aggregated then there should be no differences of opinion. In the NOT SETS condition there is little difference in decisions, reflecting the theory that all information had become public.

A surprisingly strong similarity exists between the efficiency results and data obtained in the field from racetrack parimutuel betting. On one hand, the correlation between the implicit price and the objective winning probability is very high, especially in the NOT SETS information structure. This weak form of statistical efficiency is reported frequently in field studies. On the other hand, a well known bias that exists in the field is also present in the experimental data.

OBSERVATION 1. The 'favorite/longshot' biases are present in the data; although, the biases are less pronounced in the experimental data than in field data.

\footnotetext{
${ }^{12}$ This analysis ignores the fact that within one period subjects' profits are correlated, as the sum of the profits is always equal to $-\mathrm{H}$.

${ }^{13}$ It should be noted that this result might be due to the small difference in information advantage between agents.
} 
Notice from Tables 3 and 4, that the implicit prices of the 1 st are slightly too low, relative to the frequency of winning, and the implicit prices of the 6th are slightly too high. This means that the longshot has been overvalued, whereas the favorite has been undervalued. The slight nature of the effect can be seen by observing, for example, that in the NOT SETS condition, the effect goes away if the three top-ranked markets are considered.

\section{B. Measures of information aggregation in prices}

The statistical measure of efficiency cannot be used to measure information aggregation. Information aggregation is the relationship among information held at the individual level and information reflected in prices. Any measure of aggregation must be based on the information that exists to be aggregated. For example, a premature conclusion derived from the results in the previous section would suggest that the parimutuel mechanism, especially in the NOT SETS condition, did an effective job of aggregation. Such a conclusion would be premature because the statistical efficiency measures do not incorporate the nature of the information that exists to be aggregated and therefore cannot measure the amount that takes place. Furthermore, conclusions reached by using statistical efficiency measures make sense only on average. They do not provide arguments that for every market period information has been aggregated.

RESULT 3. Information aggregation has clearly taken place in the NOT SETS condition. Whether or not information aggregation has taken place in the PIC cases depends upon the choice of baseline. If either the Competitive Equilibrium Private Information Opinion or the Average Opinion is used as the baseline, then one can conclude that aggregation has also taken place in the PIC case.

SUPPORT. Tables 6 and 7 contain the distance from AIA to each of the four baseline measures as well as the implicit prices reflected in the final odds. The Würtz measure is used for both sets of experiments, whereas the Kullback-Leibler measure can only be computed for the PIC parameters. Thus, Tables 6 and 7 provide measures of the average degree of aggregation of the information that took place in the markets.

For the NOT SETS condition, the information measure based on implicit prices is at least two times smaller than the ones based on any of the proposed baselines. For example, the average Würtz distance from AIA to the Average Opinion is 0.722 , while the Würtz distance from AIA to the implicit prices derived from the final odds is 0.331 . In this case the Average Opinion is over twice as far from AIA than are the implicit prices. As a formal test, one can use an exact sign test to test the hypothesis that the distances are equal. At a 5\% level, this hypothesis is rejected in favor of the hypothesis that the distance from implicit prices to AIA is the smallest. That is, the implicit prices are closer to the Aggregate Information Available than are any of the potential baselines.

In the PIC, the Wuirtz measure of the distance from AIA to implicit prices is generally smaller than the distance from AIA to any of the potential baselines ( the DTPI, the CEPI Opinion, and the Average Opinion) except the ex-post Best Opinion. In the PI-4 
condition, these effects are significant for the CEPI and the Average Opinion. The Best Opinion is always closer to the truth than the implicit prices. In the PIC-4 this effect is not significant, but it is at a 5\% level in the PIC-2. It is clear from the tables that information aggregation under the PIC is not as good as in the NOT SETS condition.

The first three results answer the first question. Yes, the parimutuel can successfully aggregate information. In the NOT SETS condition, this aggregation process is significantly better than one would expect from private information models. Moreover, every bettor's ex ante opinion, i.e. his opinion before any betting took place, is improved by the implicit prices. In the PIC, aggregation occurs, although the market does not do an effective job compared to the NOT SETS condition. It usually outperforms the private information models, but in most periods one can identify betters who have a 'better' opinion before betting than does the market after the period is over. The comparison between experimental conditions is formally shown by a Mann-Whitney test. This test shows that aggregation in the NOT SETS condition is significantly better than aggregation in the PIC at a 5\% level. Additionally, information aggregation is only slightly better in the PIC-2 than in the PIC-4. Broadly speaking, we do not have evidence that the longer that subjects are uncertain about the termination of the market, the more information that is aggregated in prices.

The results also partially answer the second question concerning the principles that best describe the aggregation process. Result 4 summarizes model accuracy. As will be shown, the CERE model is the best in the NOT SETS condition, whereas private information models fit the data best in case of the PIC condition. Such a conclusion produces a paradox. How could the information be aggregated while private information models fit the data the best? The result is followed by a series of observations and results that explore the nature of the evidence.

RESULT 4. In the NOT SETS condition the Competitive Equilibrium Rational Expectations model is the most accurate of the models considered. In the PIC condition the most accurate models are the private information models, and the Competitive Equilibrium Rational Expectations model is the least accurate.

Tbl. 8 Tbl. 9
SUPPORT. Tables 8 and 9 contain the average distance of the predictions of each of the four models from the observed implicit prices. Using the Würtz measure the predictions of the Competitive Equilibrium Rational Expectations model are on average 0.331 away from the actual prices in the NOT SETS condition, whereas the private information models are further away from the implicit prices. Thus, in this sense, the predictions of the Competitive Equilibrium Rational Expectations model are closer. However, in the PIC the private information models are closer. For example, the Decision Theory Private Information model has a distance of 0.275 from implicit prices in the PIC-4, whereas the Competitive Equilibrium Rational Expectations model is 0.485 away from implicit prices. 
Results 3 and 4 lead to an interesting question. How can the information be aggregated in the PIC, a conclusion that can be supported by Result 3, when the most accurate behavioral models such as the Decision Theoretic Private Information Model, is based on a principle that assumes that no aggregation at all is taking place? This seeming inconsistency of results forces a somewhat deeper look at the data that must be accompanied by a realization that no clear explanation why information aggregation occurs can be developed from this data set and theory. The section that follows includes observations and results that might form the basis for new studies. These observations lead to the conjecture that private information models may be the most accurate in the sense of averages and in the sense of prices, but cannot explain certain other features of the data. These "other features" suggest that individuals are actually behaving strategically.

\section{Additional results}

The first question posed is whether or not individuals are investing all of their money. The experiments are designed to make sure that participation has a positive expected value. Recall that the "house take" was negative. If individuals are risk neutral, and are not engaged in strategic or learning behavior, then they should invest up to the limits of their capacities to invest. The next result shows that individuals did not fully invest, and, more interestingly, invested less in the PIC than in the NOT SETS condition.

RESULT 5. Individuals invest approximately $75 \%$ of their endowments in the NOT SET condition and approximately $60 \%$ in the PIC.

SUPPORT. The data are in Table 10. The proportions for individual experiments are reported in the other rows. They tell us that betters do not fully invest, and more interesting, invest less in the PIC than in the NOT SETS condition. An explanation for the former might be caused by the risk attitude of the betters, but the failure to fully invest is also consistent with strategic behavior where betters wait too long and experience the closure of the market before they can spend their total budget. The difference in investment between the NOT SETS and the PIC might be due to the complexity of the PIC. Contrary to the NOT SETS condition, knowledge of all information is not sufficient to know the winning market in the PIC. Therefore, bets entail more risk in the PIC. This might prevent risk-averse betters from investing their complete budgets. However, it should be noticed that the experienced betters in the PIC experiment 061996 invest as much as in the NOT SETS condition. They invest $72 \%$ of their budget in tickets.

The second question to pose is whether or not there is direct evidence that strategic behavior is taking place. The models based on private information require no learning or strategic behavior. Result 6 makes clear that strategic behavior exists and is significant. As has been noticed in theoretical work (e.g. Palfrey and Srivastava, 1986), every subject has an incentive to disguise his private information. Revealing one's private information enables other subjects to improve their beliefs about which state will occur. Briefly put, individuals have an incentive to bluff or 'lie' about their private information by investing 
in markets that they think will not win, in hope of attracting investments in those markets. They also have an incentive to wait and try to learn from others while revealing nothing about their own information.

RESULT 6: Evidence exists for strategic behavior in waiting strategies and in bluffing.

SUPPORT. The private information models suggest that neither waiting nor bluffing should exist in the markets. On the other hand, individuals that are interested in the information obtained from the decisions of others have an incentive to wait until the last seconds before investing and they should have no interest in investing in "bluffing" in an

Tbl.11 attempt to mislead other individuals. Table 11 addresses the issue of the timing of spending. It contains data about the proportion of spending that occurred during various parts of a period. It is clear that especially in the NOT SETS condition, waiting is overwhelming. Most trading occurs in the last seconds before and after the four minute time mark.

Tbl.12

The issue of bluffing is addressed by the data in Table 12. In the NOT SETS condition, bluffing about one's private information can be viewed as purchases of tickets in markets that are excluded by one's private information. Table 12 shows that such strategic purchases actually occur, although the amount involved with those purchases is negligible. The proportions of instances in which strategic behavior can be identified is about $18 \%$ but the percentage of money involved is only $2 \%$ of the total spending.

These strategic purchases directly negatively influence the information aggregation properties of the market. Failure to invest until the last second would seem to work against information aggregation because it delays the information and gives it less chance to become integrated. Indirectly, these actions along with the bluffing and lying can also harm information aggregation as they can have a negative impact on other subjects' beliefs. The next result provides a glimpse of the complexity.

RESULT 7. Bluffing works against information aggregation.

SUPPORT. In these experiments, the correlation coefficient between the number of strategic purchases as a fraction of the total number of transactions is negatively correlated with the Würtz-measure of information aggregation, in two of the three experiments with a NOT SETS condition. Table 13 contains the statistics.

The constellation of results above helps to formulate some conjectures. The first conjecture is that convergence is taking place toward the predictions of the Competitive Equilibrium Rational Expectations model.

CONJECTURE 1. As periods and experience progress, the implicit prices are moving in the direction of the AIA, and the Competitive Equilibrium Rational Expectations model is becoming more accurate relative to other models. 
SUPPORT. The conjecture has two parts. The first part is addressed by the data in Table 14. The average Würtz distance from AIA decreases with time under both experimental conditions. For example, in the NOT SETS condition the distance is 0.464 on average after one-third of all bets are realized, but has decreased to 0.331 by the time that the experiment ends. In the PIC-2 the distance of .553 after the first $1 / 3$ of all bets were realized becomes reduced to .452 by end.

Tbl.15 The second part of the conjecture is addressed by the data in Table 15. The table shows the average Würtz distance of the predictions of the various models from the implicit prices. Again, these measurements are made for times when one-third of all bets are realized, two-thirds of all bets are realized, and at the end of the market period. As can be seen, under all experimental conditions the predictions of the Competitive Equilibrium Rational Expectations Model get consistently closer to the actual implicit prices as time increases. This convergence is significantly stable in the direction of the AIA, except for the second phase in the PIC-2 but even there it is in the AIA direction. Under none of the conditions do any of the other models move closer to the AIA. Other models demonstrate either no consistent convergence pattern or actually converge away from the implicit prices.

While the conjecture may be true on average, it would be a mistake to claim that the convergence process is uniform or always present. The next observation demonstrates that the rational expectations story is not in any sense complete or reliable in every instant.

\section{OBSERVATION 2. Herding can occur.}

SUPPORT. Herding occurs when a clearly wrong market attracts most of the investment. Period 11 of experiment 113095 is an example. The implicit prices are shown in Figure 3-A,B. In this period of the experiment several agents developed opinions that the state was SX, but it was not. The dynamic is also suggested when the market with the highest price continues to experience price increases and the market with the lowest price experiences decreases. Table 16 and Table 17 demonstrate the existence of the dynamic. Under both the NOT SETS condition and PIC the maximum implicit price is, on average, increasing and the minimum implicit price is, on average, decreasing. However, even though the existence of the phenomena can be demonstrated, its pervasiveness can be solidly rejected. In the NOT SETS condition, the maximum implicit price is generally close to one, but the market with the maximum price is not arbitrary. In 29 of 38 market periods the market with the highest price is also the true state. Even though the learning can be wrong, for the most part it is right. 


\section{CONCLUDING REMARKS}

This study inquires about the possibility of designing parimutuel type betting. systems to aggregáte information held by decentrally located agents. The first question posed was whether or not it could be done. The second question was whether or not standard models could be used to understand what is observed. The hope is that information aggregation success, accompanied by a deeper understanding of the reasons for success, will lead to improved designs.

The study began by looking at parimutuel systems found occurring naturally in the field and at aspects of theory for suggestions about what might be expected. From the field one can get, at best, hints about the general properties of information aggregation. Existing parimutuel systems were designed for entertainment purposes and whether or not they successfully aggregate information cannot be known because the critical parameters are unknown for purposes of analysis. Nevertheless what is known about the behavior of

parimutuel systems found in the field and the methods of observation, was very helpful in this study. Theory was helpful but we cannot really claim that the mechanism that we developed was designed from first principles since we do not know what those are. Indeed, there is no clear theoretical reason why parimutuel systems should aggregate information at all. Thus, the mechanism design reflected observations that came from naturally occurring events, theory and a long history of laboratory work.

Since very little is known, a sequential approach was adopted. After the major features of the parimutuel process were determined, the experiments began with environments that were on the "boundary" of experiments in which information aggregation had been observed in asset market experiments. Initial successes then encouraged the study of environments that are much more complex, from an information aggregation point of view, than anything that has been studied to date.

The first conclusions reached by this exploratory analysis are promising. Information aggregation over several chosen "baselines" can clearly be observed (Result 3).

However, in the more complex environments, the results contain ambiguities. The support for any claim that information aggregation has taken place depends upon the baselines chosen for "no aggregation".

Analysis of behavior (Result 4) demonstrates that the "simplest" environment resulted in strong support for the Competitive Equilibrium Rational Expectations model. This model was most accurate relative to models in which individuals myopically base decisions on private information alone. The implicit prices were very close to the prices that would exist if all agents pooled their information and made decisions on the basis of the pooled data. However, in the more complex environments the most accurate model, based on average predictions, is a decision theoretic model based on myopic individual decision behavior in which the individual simply spends all of the money on the option that is most likely according to the individual's private information. 
The paradox created by the contradictory results stimulated deeper studies of the data to determine if individuals were indeed behaving myopically or whether the averages were masking events. On the one hand there is evidence that people do not act myopically and in isolation. They do not necessarily spend all of their money as would a risk neutral decision maker (Result 5). They engage in waiting behavior, suggesting an interest in learning form others and they also engage in bluffing behavior (Result 6). Thus, they demonstrate a sensitivity to the existence of others and the possibility that the actions of others may contain useful information and that others are looking to them for the same purposes.

On the other hand, bluffing works against information aggregation (Result 7).

Nevertheless, a conjecture is developed that, with experience, implicit prices are moving toward full revelation and behavior is moving toward that predicted by the Competitive Equilibrium Rational Expectations Model (Conjecture 1).

The general pattern seems to be for individuals to "jump on" the favorite with the crowd and "jump off" of the least active markets in a manner typical of herding. In fact, bubbles can occur (Observation 2) but they are by no means a pervasive part of the data.

Although phenomena (the occurrence of bubbles and "disaggregation" of information) characteristic of herding behavior are observed, the overall picture drawn by these experiments is that parimutuel markets do have the capacity to aggregate the widely dispersed information held by the subjects.

Interestingly enough, the data in the laboratory has some of the major features of the field data (Result 1) including some well known biases such as the favorite/longshot bias (Observation 1). Evidently, looking to field data for hints was not a bad idea. Parenthetically, these results suggest that the biases found in field data may result for entirely different reasons from biases in individual decision making. Since the subjects were given the computations from Bayes' Law, the role of individual decision biases in the experiment was substantially reduced.

One must be concerned with the question, "can improved mechanisms can be designed?" One possible improvement is a mechanism to allow subjects to sell back their tickets in some sort of open market. Such a mechanism may increase the informational efficiency. This suggestion is based on the belief that information aggregation in ordinary securities markets also relies on the information revealed by bids and asks (limit orders) that are observed by all agents but might not be successful. In parimutuel markets such information is not available. Every action directly influences one's budget. In order to explore the implications of this intuition, two periods (period 17 and 18 in experiment 061996) were designed to allow subjects to sell back their tickets at any moment they wanted. In the first of the two periods, subjects did not use the sell-back provision. The gross tickets sales (3890 tickets) was not much higher than the net tickets sales (3219 tickets). In the second period of the two, the sell-back provision was used actively. The gross tickets sales (6423 tickets) was considerably higher than the net tickets sales (4047 tickets). Is information aggregation taking place? Table 18 shows the Würtz measure of 
distance from implicit prices to AIA at various times in both periods. If we attribute the results of period 17 to lack of experience, the results in period 18 are simultaneously disappointing and promising. The bad news is that, overall, market prices are not closer to the AIA as in similar conditions where the sell-back option was not available. The good news from period 18 is that the convergence process is much faster. Even at the end, considerable improvement in aggregation is observed. Of course, the limitations of these data are considerable and are presented here only to stimulate further research and thought about the problem.

The parimutuel institution is a powerful device for aggregating information. Whether or not versions can be invented that improve upon the version we designed and tested remains to be seen. Many aspects of the mechanism are not understood. In particular the role of risk-aversion may be to bias prices and the possible information contained in the fact that not all budgets were invested has not been studied. Clearly the models of the process are simple compared to the complexity of the process. How experience or special talents for operating within the process might influence the capacity of the mechanism to perform is an open question. Nevertheless, even though many questions exist, the power of the mechanism to aggregate information has been established. 


\section{APPENDIX A}

\section{Instructions}

This is an experiment in the economics of market decision making. Various research foundations have provided funds for this research. If you follow the instructions carefully and make good decisions, you might earn a considerable amount of money, which will be paid to you in cash. The currency in these markets is francs. All francs will be converted to dollars at the end of the experiment, at a rate of francs $=1$ US dollar.

In this experiment we are going to conduct several markets in which you will participate for a number of periods. Each period, there are markets open for trading; this number will be announced at the beginning of each period. In the markets you will be able to purchase tickets to a lottery that pays according to the event that occurs at the end of the period. Each market is associated with a particular event. The lottery payoff will be shared by those that hold winning tickets in proportion to the number of tickets purchased. In addition, there will be a 'bonus prize' that is shared the same way. In the experiment, the bonus prize is francs.

Consider an example with three markets labeled A, B, and C and a "bonus prize" of 27 francs. Market A is associated with 'event A', market B is associated with 'event B' and market $C$ is associated with 'event $C$ '. Suppose that the tickets in each market are sold at $1 \mathrm{franc}$ each. Suppose further that you purchase 3 tickets in market B and 0 tickets in each of the other two markets. Suppose that a total of 9 tickets are sold in market B (three are sold to you and six are sold to other people); a total of 3 tickets are sold in market A (all 3 are sold to other people); a total of 6 tickets are sold in market $C$ (all 6 are sold to other people). Thus a total of 18 tickets are sold in all markets together. These purchases are shown in the table below in columns 1 and 2.

\begin{tabular}{|c|c|c|c|c|c|c|}
\hline & 1 & 2 & 3 & 4 & 5 & 6 \\
\hline & $\begin{array}{c}\text { tickets you } \\
\text { purchased in } \\
\text { market }\end{array}$ & $\begin{array}{c}\text { all tickets } \\
\text { purchased in } \\
\text { market }\end{array}$ & $\begin{array}{c}\text { lottery payoff } \\
\text { multiple }\end{array}$ & $\begin{array}{c}\text { bonus payoff } \\
\text { multiple }\end{array}$ & $\begin{array}{l}\text { total of payoff } \\
\text { multiples }\end{array}$ & total pay off \\
\hline $\mathrm{A}$ & 0 & 3 & & & & \\
\hline $\mathrm{B}$ & 3 & 9 & & & & \\
\hline $\bar{C}$ & 0 & 6 & & & & \\
\hline & & $\begin{array}{c}\text { total tickets } \\
\text { sales }=18\end{array}$ & & & & \\
\hline
\end{tabular}

The pattern of ticket sales determines two different types of payoff multiples, a lottery payoff multiple and a bonus payoff multiple. Your payoff for each winning ticket you hold is the sum of these two multiples. That is, your payoff for each winning ticket you hold is the lottery payoff multiple plus the bonus payoff multiple. Thus 
your total payoff $=$ (lottery payoff multiple + bonus payoff multiple) times the number of winning tickets you hold.

The lottery payoff multiple, the lottery payoff per winning ticket, is the total of all tickets sold in all markets, divided by the number of tickets sold in the winning market. In the example the total number of tickets sold is 18 .

Suppose that event B occurs. Then the tickets in market B are the winning tickets. The number of winning tickets is 9 . Thus, as shown in column 3 , the lottery payoff multiple is $18 / 9=2$.

The bonus in the example is 27 francs. The bonus payoff multiple is the amount of the bonus per winning ticket. That is, the bonus payoff multiple is the bonus divided by the number of tickets sold in the winning market as shown in column $4,27 / 9=3$.

Thus the total of payoff multiples, shown in column 5 , is the lottery payoff multiple of 2 plus the bonus payoff multiple of 3 . That is, the total of payoff multiples is $2+3=5$. Your payoff from the winning tickets that you hold is the total of payoff multiples times the number of winning tickets that you hold. In the example this is 5 times 3 winning tickets $=15$. Those that hold tickets in market $\mathrm{A}$ and $\mathrm{C}$, which are not winning markets, would receive nothing for these tickets.

\begin{tabular}{|c|c|c|c|c|c|c|}
\hline & & & & \multirow{2}{*}{$\frac{\text { bonus }=27}{4}$} & \multirow{2}{*}{5} & \multirow[b]{2}{*}{6} \\
\hline & 1 & 2 & 3 & & & \\
\hline & $\begin{array}{l}\text { tickets you } \\
\text { purchased in } \\
\text { market }\end{array}$ & $\begin{array}{c}\text { all tickets } \\
\text { purchased in } \\
\text { market }\end{array}$ & $\begin{array}{l}\text { lottery payoff } \\
\text { multiple }\end{array}$ & $\begin{array}{l}\text { bonus payoff } \\
\text { multiple }\end{array}$ & $\begin{array}{c}\text { total of payoff } \\
\text { multiples }\end{array}$ & total payoff \\
\hline $\mathrm{A}$ & 0 & 3 & & & & \\
\hline $\mathrm{B}$ & 3 & 9 & $18 / 9=2$ & $27 / 9=3$ & $2+3=5$ & $5 \times 3=15$ \\
\hline $\mathrm{C}$ & 0 & 6 & & & & \\
\hline & & $\begin{array}{l}\text { total tickets } \\
\text { sales }=18\end{array}$ & . & & & \\
\hline
\end{tabular}

\section{Record Sheet}

Attached you will find a record sheet. This will help you with the decisions you make. At the beginning of a period you will be given francs. You will find this in the upper right of your computer screen as cash on hand. You can use these francs to purchase tickets in markets of your choice or you can simply hold the cash as you wish. At the end of the period you will be required to return francs to the experimenter. This amount will be found at the bottom of the record sheet in the row labeled payment to the experimenter. At the end of each period, record your purchases in each market. You should also write the payoff multiples for each market, which are recorded by the experimenters. After the winning market is announced, calculate your total payoff (winning tickets times total of payoff multiples). Add your francs on hand to the total payoff, and then subtract the payment to the experimenter of . The difference is your earnings for the period. Write these earnings also in the payout sheet. 
Suppose you had been given 50 francs at the beginning of the period and that you are required to return 30 at the end of the period. Suppose further that your purchases are as described in the example above. The appropriate entries you should make are in the table below. In the first column, you record your purchases. Then, you have to record the payoff multiples, which will be announced by the experimenter.

\begin{tabular}{|c|c|c|c|c|c|c|}
\hline & $\begin{array}{l}\text { tickets you } \\
\text { purchased } \\
\text { in market }\end{array}$ & $\begin{array}{c}\text { lottery } \\
\text { payoff } \\
\text { multiple }\end{array}$ & $\begin{array}{c}\text { bonus } \\
\text { payoff } \\
\text { multiple }\end{array}$ & $\begin{array}{c}\text { total of } \\
\text { payoff } \\
\text { multiples }\end{array}$ & $\begin{array}{c}\text { winning } \\
\text { market }\end{array}$ & total payoff \\
\hline A & 0 & 6 & 9 & 15 & & \\
\hline $\mathrm{B}$ & 3 & 2 & 3 & 5 & $\mathrm{X}$ & 15 \\
\hline $\mathrm{C}$ & 0 & 3 & 4.5 & 7.5 & & \\
\hline & & & & & & \\
\hline.. & & & & & & \\
\hline .. & & & & & & \\
\hline & & \multicolumn{4}{|c|}{+ total cash on hand } & 47 \\
\hline & & \multicolumn{4}{|c|}{ total cash on hand plus total payoff } & 62 \\
\hline & & \multicolumn{4}{|c|}{ - payment to the experimenter } & 30 \\
\hline & & \multicolumn{4}{|c|}{ total earnings } & 32 \\
\hline
\end{tabular}

Suppose that event B occurs. Then market B is the winning market, which is indicated by an ' $\mathrm{X}$ '. You can calculate now your total payoff, winning tickets times the total of payoff multiples. You purchased 3 tickets, so you spent 3 francs. Thus, your cash on hand will be the amount given to you at the beginning of the period, minus 3 francs $=50-3=47$ francs. Thus, your total cash on hand plus total payoff is $47+15=62$. The payment to the experimenter is equal to 30 francs. Thus your total earnings in this period is $62-30=32$.

\section{Events}

The event associated with a period, will be announced at the end of the period. The event has been pre-chosen using a random number table, which you may inspect after the experiment. Every possible event is equally likely to occur (i.e. if you repeat this experiment over and over again, the fraction of the times that each event occurs is the same). 


\section{Procedures}

At the beginning of each period one of the experimenters will offer a total of tickets for sale at each market for 1 franc for each ticket. The number of tickets and the price can be read in the 'Ask' window of your screen. At any time, as someone purchases a certain number of tickets at a market, the total amount of tickets for sale at that market drops by this number. These numbers enable you to calculate the payoff multiples as they change. The number of tickets sold at each market and the total of payoff multiples will also be repeated on the whiteboard.

Purchases can be made using the $<\mathrm{Ctrl}><\mathrm{F} 1>$ keys. Do not use the $<\mathrm{F} 3>$ key.

\section{Period timing}

Each period will last a minimum of minutes and a maximum of minutes; the exact time is randomly chosen by using a random number table; every time within the minimum and maximum time is equally likely to occur.

\section{Information about events}

There will be six markets, labeled SX, SY, SZ, TX, TY, and TZ. Each market is represented by two names, a first name and a second name. The first name is either $S$ or T. The second name is either X, Y, or Z. Events are associated with markets; market SX is associated with 'event SX', market SY is associated with 'event SY', and so on.

Before the period begins, information about the event that occurs will be distributed. Some people will be given the first name of the event that occurs. Other people will be given information that eliminates for possibility of one of the three second names. All information combined, completely determines the name of the event that occurs. Suppose that the event, which has been randomly drawn, is 'event SY'. Then the following types of information cards will be in the box:
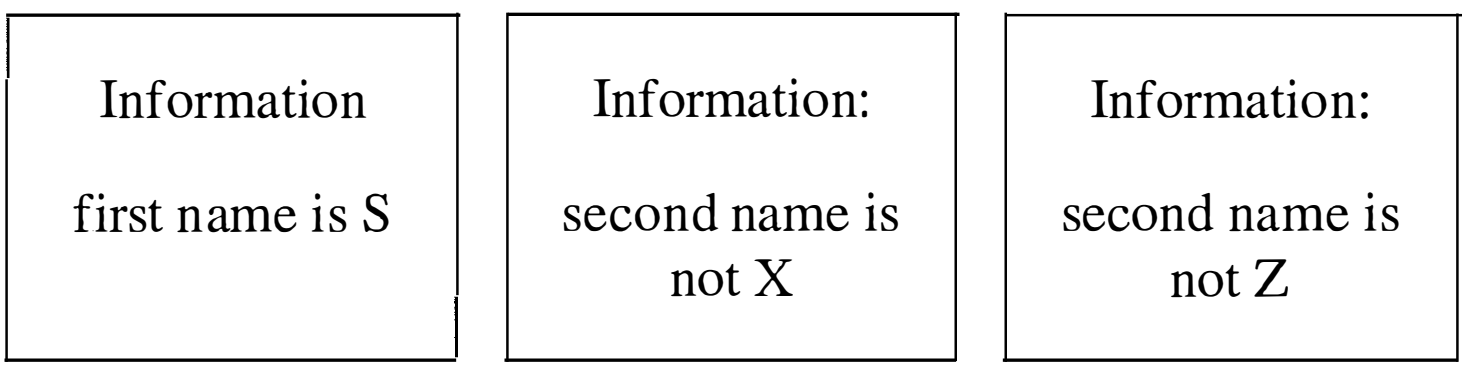

There will be an equal number of each card in the box. The number of people who draw each card will be the same. 


\section{APPENDIX B:}

\section{Private Information}

In the NOT SETS condition, the following slips were distributed.

\begin{tabular}{|l|l|}
\hline Information: & Information: \\
first name is $S$ & first name is T \\
\end{tabular}

\begin{tabular}{|l|c|}
\hline Information: & Information: \\
second name is not $\mathrm{X}$ & Information: \\
\hline
\end{tabular}

In the PIC, information slips had the following particular form:

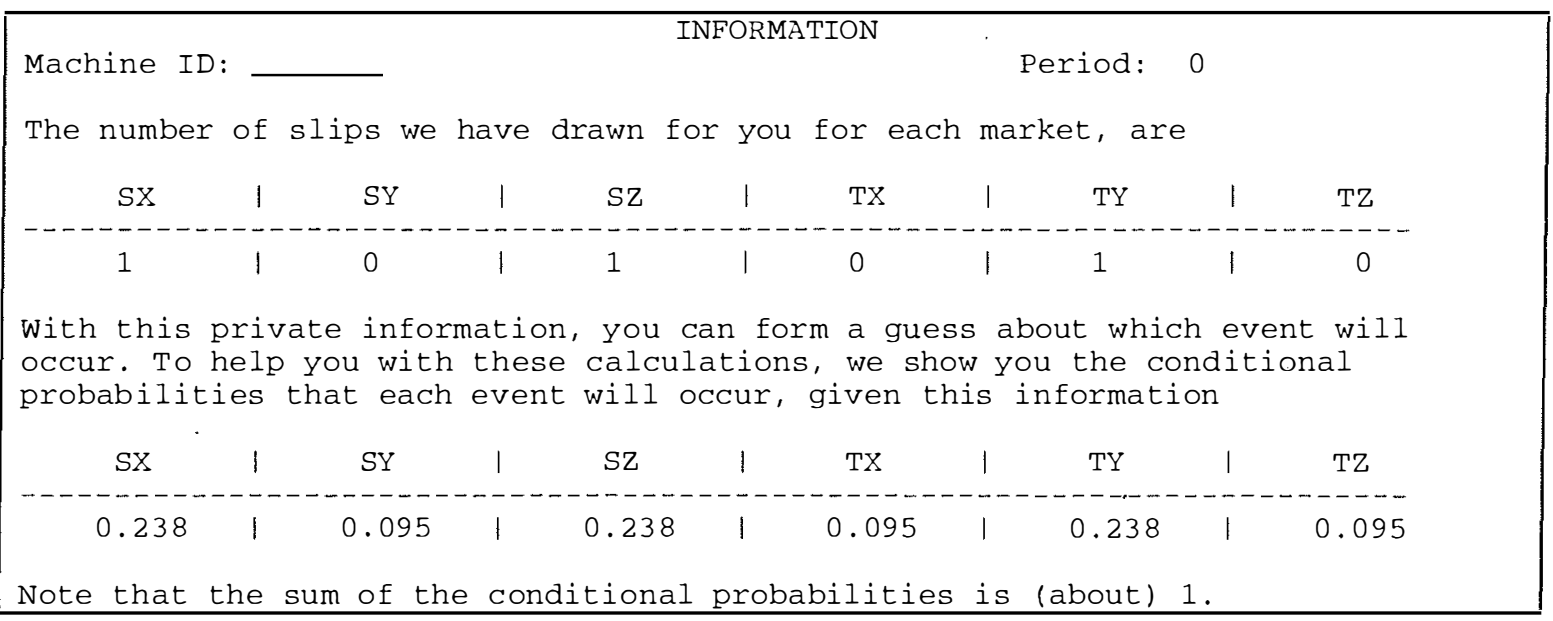


APPENDIX C: Record Sheet

\section{RECORD SHEET}

\begin{tabular}{|l|l|}
\hline Name & \\
\hline Machine ID \# & \\
\hline Period & \\
\hline Information & \\
\hline
\end{tabular}

\begin{tabular}{|l|l|l|l|l|l|l|}
\cline { 2 - 7 } & \begin{tabular}{|l|l|l|l|} 
tickets you \\
purchased \\
in market
\end{tabular} & $\begin{array}{c}\text { lottery } \\
\text { payoff } \\
\text { multiple }\end{array}$ & $\begin{array}{c}\text { bonus } \\
\text { payoff } \\
\text { multiple }\end{array}$ & $\begin{array}{c}\text { total of } \\
\text { payoff } \\
\text { multiples }\end{array}$ & $\begin{array}{c}\text { winning } \\
\text { market }\end{array}$ & total payoff \\
\hline SX & & & & & & \\
\hline SY & & & & & & \\
\hline SZ & & & & & & \\
\hline TX & & & & & & \\
\hline TY & & & & & & \\
\hline TZ & & & & & & \\
\hline
\end{tabular}




\section{APPENDIX D}

\section{An Example of the Concepts}

To illustrate the different concepts used in this paper, consider the following example. Three individuals denoted by A, B and C, are given the following information slips in the probabilistic information condition (PIC). In the table below, each cell (i,j) denotes the number of times state $\mathrm{j}$ occurs in i's sample. For example, individual A receives the sample $\{\mathrm{SX}, \mathrm{SZ}, \mathrm{TX}\}$.

\begin{tabular}{l|c|c|c|c|c|c} 
& $\mathrm{SX}$ & $\mathrm{SY}$ & $\mathrm{SZ}$ & $\mathrm{TX}$ & $\mathrm{TY}$ & $\mathrm{TZ}$ \\
\hline $\mathrm{A}$ & 1 & 0 & 1 & 1 & 0 & 0 \\
\hline $\mathrm{B}$ & 0 & 2 & 1 & 0 & 0 & 0 \\
\hline $\mathrm{C}$ & 0 & 0 & 1 & 0 & 1 & 1
\end{tabular}

The prior probability of each state is known to be $1 / 6$ and the conditional probabilities of a sample given the state are known and are given in the text. Thus, by an application of Bayes Law, given these information slips, each individual is able to update his/her beliefs about the state that occurs. These beliefs, captured by the concept private information, are described in the following table. Each cell $(\mathrm{i}, \mathrm{j})$ gives i's conditional probability that state $\mathrm{j}$ is the state that occurs, given i's information slip.

\begin{tabular}{l|c|c|c|c|c|c} 
& $\mathrm{SX}$ & $\mathrm{SY}$ & $\mathrm{SZ}$ & $\mathrm{TX}$ & $\mathrm{TY}$ & $\mathrm{TZ}$ \\
\hline $\mathrm{A}$ & 0.238 & 0.095 & 0.238 & 0.238 & 0.095 & 0.095 \\
\hline $\mathrm{B}$ & 0.078 & 0.490 & 0.196 & 0.078 & 0.078 & 0.078 \\
\hline $\mathrm{C}$ & 0.095 & 0.095 & 0.238 & 0.095 & 0.238 & 0.238
\end{tabular}

All information in the system is contained in the information slips held by individuals. If this information is collected and pooled, Bayes Law can be applied to the pooled data to get the best possible estimate of the state given the information that exists. This pooled and processed information is called the Aggregate Information Available (AIA). This distribution is described below. Each entry describes the conditional probability that the state occurs, given the information on all information slips.

\begin{tabular}{l|c|c|c|c|c|c} 
& $\mathrm{SX}$ & $\mathrm{SY}$ & $\mathrm{SZ}$ & $\mathrm{TX}$ & $\mathrm{TY}$ & $\mathrm{TZ}$ \\
\hline AIA & 0.078 & 0.196 & 0.490 & 0.078 & 0.078 & 0.078
\end{tabular}

Of course AIA is unknown to the individuals who hold their information slips privately and must make decisions on the information on their own slip together with anything that is signaled from the economic activity that takes place in the parimutuel betting process. Several different models predict the individual behavior that will be observed. Given the distribution of private information among individuals, the models give unique predictions about the implicit prices that will prevail at the end of the parimutuel betting period. 
First, the Decision Theory Private Information Model (DTPI) assumes that each individual invests his/her total budget on the state that is most likely to occur according to the private information. In case of ties between states, it is assumed that the individual equally divides his/her budget between these most likely states. The following table shows individual investments in each market as a fraction of total individual investment. The implicit prices automatically follow from these individual decisions.

\begin{tabular}{l|c|c|c|c|c|c} 
& $\mathrm{SX}$ & $\mathrm{SY}$ & $\mathrm{SZ}$ & $\mathrm{TX}$ & $\mathrm{TY}$ & $\mathrm{TZ}$ \\
\hline $\mathrm{A}$ & 0.333 & 0 & 0.333 & 0.333 & 0 & 0 \\
\hline $\mathrm{B}$ & 0 & 1 & 0 & 0 & 0 & 0 \\
\hline $\mathrm{C}$ & 0 & 0 & 0.333 & 0 & 0.333 & 0.333 \\
\hline $\begin{array}{l}\text { Implicit } \\
\text { Price }\end{array}$ & 0.111 & 0.333 & 0.222 & 0.111 & 0.111 & 0.111
\end{tabular}

Next, the Competitive Equilibrium Private Information Model (CEPI) predicts a price pattern that is rationalized by individuals maximizing their expected profits, given the implicit prices and their private information. They are assumed to not condition their beliefs about states on the prices that they observe. In the table below the unique price prediction is given. Individual investment in a market as a fraction of total individual investment follows from these prices, and also generates these prices.

\begin{tabular}{l|c|c|c|c|c|c} 
& $\mathrm{SX}$ & $\mathrm{SY}$ & $\mathrm{SZ}$ & $\mathrm{TX}$ & $\mathrm{TY}$ & $\mathrm{TZ}$ \\
\hline $\mathrm{A}$ & 0.4 & 0 & 0.2 & 0.4 & 0 & 0 \\
\hline $\mathrm{B}$ & 0 & 1 & 0 & 0 & 0 & 0 \\
\hline $\mathrm{C}$ & 0 & 0 & 0.2 & 0 & 0.4 & 0.4 \\
\hline $\begin{array}{l}\text { Implicit } \\
\text { Price }\end{array}$ & 0.133 & 0.333 & 0.133 & 0.133 & 0.133 & 0.133
\end{tabular}

Third the Proportional Allocation assumes that each individual invests in proportion to his/her private information. In the example, this model generates the following prediction. Notice that the implicit prices are the averages of the beliefs of the individuals. Later this will be termed the Average Opinion.

\begin{tabular}{l|c|c|c|c|c|c} 
& SX & SY & SZ & TX & TY & TZ \\
\hline $\mathrm{A}$ & 0.238 & 0.095 & 0.238 & 0.238 & 0.095 & 0.095 \\
\hline $\mathrm{B}$ & 0.078 & 0.490 & 0.196 & 0.078 & 0.078 & 0.078 \\
\hline $\mathrm{C}$ & 0.095 & 0.095 & 0.238 & 0.095 & 0.238 & 0.238 \\
\hline $\begin{array}{l}\text { Implicit } \\
\text { Prices }\end{array}$ & 0.137 & 0.227 & 0.224 & 0.137 & 0.137 & 0.137
\end{tabular}

Finally, the Competitive Equilibrium Rational Expectations Model predicts that individuals will invest such that implicit prices coincide with the AIA. Individual investments should satisfy this price condition, but any individual investment generating these prices serves as a model prediction. 
The models can be used to understand the nature of behavior but a notion of information aggregation and revelation is also needed. For this purpose the behavioral models also produce baseline standards for a concept of "no information aggregation". The implicit prices deduced from the applications of the various behavioral model can be viewed as "opinions" as expressed by the markets. The DTPI Opinion, the CEPI Opinion, and the Average Opinion are described by the implicit prices from the DTPI model, the CEPI model, and the Proportional Allocation Model respectively. The Best Opinion coincides with the private information closest to the AIA. In a sense, if these prices prevail, one might conclude that the behavior exhibited in the markets reflected no aggregation of information at all beyond that privately held.

The information content of these opinions can be measured in terms of their "distance" from AIA. Below, one can read the individual distances from private information to AIA for both the Würtz measure as the Kullback-Leibler measure. Under both measures, B's private information is closest to the AIA, and accordingly, B's private information describes the Best Opinion. As can be determined from the table the

\begin{tabular}{l|c|c} 
& Würtz-measure & Kullback-Leibler measure \\
\hline $\mathrm{A}$ & 0.353 & 0.325 \\
\hline $\mathrm{B}$ (Best Opinion) & 0.294 & 0.269 \\
\hline $\mathrm{C}$ & 0.353 & 0.325 \\
\hline DTPI Opinion & 0.269 & 0.176 \\
\hline CEPI Opinion & 0.357 & 0.369 \\
\hline Average Opinion & 0.267 & 0.179
\end{tabular}

DTPI Opinion and the Average Opinion are both closer to AIA than is the Best Opinion. The CEPI Opinion is the furthest from AIA. The intuition that one can draw from these examples is that models that involve to optimization (Proportional Allocation), adjustment to the environment or prices (DTPI), or learning from the market activity (CEPI) can nevertheless produce prices that are "close" to the aggregated information that exists in the system (AIA). Thus, these baselines are difficult standards against which aggregation can be measured and assessed. 


\section{REFERENCES}

Ali, Mukhtar M., (1977), "Probability and Utility Estimates for Racetrack Bettors", Journat of Political Economy, 85, 803-815.

Ali, Mukhtar M., (1979), "Some Evidence of the Efficiency of a Speculative Market", Econometrica, 47, 2, 387-392.

Asch, Peter, Burton G. Malkiel, and Richard E. Quandt, (1982), "Racetrack Betting and Informed Behavior”, Journal of Financial Economics, 10, 2, 187-194.

Berg, Joyce, Robert Forsythe, and Thomas Rietz, (1995), "What Makes Markets Predict Well? Evidence from the Iowa Electronic Markets", forthcoming in Essays in Honor of Reinhard Selten, edited by W. Güth, Springer Verlag.

Eisenberg, Edmund, and David Gale, (1959), "Consensus of Subjective Probabilities: The Pari-Mutuel Method”, The Annals of Mathematical Statistics, 30, 165-168.

El Gamal, Mahmoud and David Grether, (1995), “Are People Baysian? Uncovering Behavioral Strategies", Journal of the American Statistical Association, December, Vol. 90, No.432, pp. 1137-1145.

Forsythe, Robert, and Russell Lundholm, (1990), "Information Aggregation in an Experimental Market”, Econometrica, Vol. 58, No.2, pp.309-347.

Hurley, William, and Lawrence McDonough, (1995), "A Note on the Hayek Hypothesis and the Favorite- Longshot Bias in Parimutuel Betting", American Economic Review, 85, 4, 949-955.

Kullback, S., and R. A. Leibler, (1952), “On Information and Sufficiency”, Annals of Mathematical Statistics, 22,79-86.

Milgrom, Paul, and Nancy Stokey, (1982), "Information, Trade, and Common Knowledge", Journal of Economic Theory', 26, 17-27.

Palfrey, Thomas R., and Sanjay Srivastava, (1986), "Private Information in Large Economies", Journal of Economic Theory, 39, 34-58.

Piron, Robert, and L. Ray Smith, (1995), "Testing Risklove in an Experimental Racetrack", Journal of Economic Behavior and Organization, 27, 465-474.

Plott, Charles. R., "Rational Individual Behavior in Markets and Social Choice Processes." The Rational Foundations of Economic Behavior, edited by K. Arrow, E. Colombatto, M. Perlaman, and C. Schmidt, London: Macmillan and New York: St. Martin's Press. Forthcoming. 
Plott, Charles R. (1994), "Market Architectures, Institutional Landscapes and Testbed Experiments", Economic Theory, 4, no. 1, 3-10.

Plott, Charles R., and Shyam Sunder, (1988), "Rational Expectations and the Aggregation of Diverse Information in Laboratory Security Markets", Econometrica, 56, 1085-1118.

Potters, Jan, and Jörgen Wit, (1995), "Bets and Bids: Favorite-Longshot Bias and Winner's Curse", mimeo, University of Amsterdam.

Rosett, Richard N., (1965), "Gambling and Rationality", Journal of Political Economy, 73, 595-607.

Scharfstein, D., and J. Stein, (1990), "Herd Behavior and Investment", American Economic Review, 80, 3, 465-479.

Snyder, Wayne W., (1978), "Horse Racing: Testing the Efficient Markets Models", Journal of Finance, 33, 1109-1118.

Sunder, Shyam, (1995), "Experimental Asset Markets: A Survey", in: Handbook of Experimental Economics, edited by John H. Kagel and Alvin E. Roth, Princeton University Press, Princeton.

Thaler, Richard H., (1992), The Winner's Curse; Paradoxes and Anomalies of Economic Life, Princeton University Press, Princeton.

Thaler, Richard H., and William T. Ziemba, (1988), "Parimutuel Betting Markets: Racetracks and Lotteries", Journal of Economic Perspectives, 2, 161-174.

Tirole, Jean, (1982), "On the Possibility of Speculation under Rational Expectations", Econometrica, 50, 5, 1163-1181.

Van der Laan, G., and L. Seelen, (1984), "Efficiency and Implementation of Simplicial Zero Point Algorithms", Mathematical Programming, 30, 196-217.

Weitzman, Martin, (1965), "Utility Analysis and Group Behavior; An Experimental Study”, Journal of Political Economy, 73, 18-26.

Welch, Ivo, (1992), "Sequential Sales, Learning, and Cascades", The Journal of Finance, 695-732.

Würtz, Allan H., (1996), "A Global Upper Bound on the Power Function”, mimeo, University of Iowa, Iowa City. 
Table 1: Parameters in All Experiments

\begin{tabular}{|c|c|c|c|c|c|c|c|}
\hline Parameters & 111995 & 112995 & 112995 & 121595 & 061896A & 061896B & 061996 \\
\hline $\begin{array}{l}\text { Number of } \\
\text { Markets K }\end{array}$ & $\begin{array}{l}3(\text { period } 0-2) \\
6(\text { period } 3-8)\end{array}$ & 6 & 6 & 6 & 6 & 6 & 6 \\
\hline $\begin{array}{l}\text { Information } \\
\text { Structure }\end{array}$ & NOT SETS & $\begin{array}{l}\text { NOT SETS } \\
\text { (period 0-16) } \\
\text { PIC } \\
\text { period 17-18) }\end{array}$ & $\begin{array}{l}\text { NOT SETS } \\
\text { (period 0-16) } \\
\text { PIC } \\
\text { (period 17-18) }\end{array}$ & $\begin{array}{l}\text { PIC } \\
\text { (period 0-16) }\end{array}$ & $\begin{array}{l}\text { PIC } \\
\text { (period 0-16) }\end{array}$ & $\begin{array}{l}\text { PIC } \\
(\text { period 0-16) }\end{array}$ & $\begin{array}{l}\text { PIC } \\
\text { (period 0-16) }\end{array}$ \\
\hline Endowment E & 100 francs & 100 francs & 100 francs & 100 francs & 100 francs & 100 francs & 100 francs. \\
\hline Loan L & 300 francs & 300 francs & 300 francs & 300 francs & 300 francs & 300 francs & 300 francs \\
\hline $\begin{array}{l}\text { House Charge } \\
\mathrm{H}\end{array}$ & -1200 francs & -1200 francs & -1500 francs & -1000 francs & -1200 francs & -1200 francs & -1200 francs \\
\hline $\begin{array}{l}\text { Number of } \\
\text { Subjects }\end{array}$ & 12 & 12 & 15 & 10 & 12 & 12 & 12 \\
\hline $\begin{array}{l}\text { Period Length } \\
\left(\mathrm{T}_{\min }, \mathrm{T}_{\max }\right)\end{array}$ & $(4,5)$ & $(4,5)$ & $(4,5)$ & $(4,5)$ & $(2,5)$ & $(2,5)$ & $(2,5)$ \\
\hline Price per ticket & 1franc & 1 franc & 1 franc & 1 franc & 1 franc & 1 franc & 1 franc \\
\hline $\begin{array}{l}\text { Initial Number } \\
\text { of Tickets for } \\
\text { Sale }\end{array}$ & 5,000 & 5,000 & 6,000 & 5,000 & 5,000 & 5,000 & 5,000 \\
\hline $\begin{array}{l}\text { Conversion } \\
\text { Rate }\end{array}$ & $\begin{array}{l}100 \text { francs }= \\
1 \text { US dollar }\end{array}$ & $\begin{array}{l}100 \text { francs }= \\
1 \text { US dollar }\end{array}$ & $\begin{array}{l}100 \text { francs }= \\
1 \text { US dollar }\end{array}$ & $\begin{array}{l}100 \text { francs }= \\
1 \text { US dollar }\end{array}$ & $\begin{array}{l}100 \text { francs }= \\
1 \text { US dollar }\end{array}$ & $\begin{array}{l}100 \text { francs }= \\
1 \text { US dollar }\end{array}$ & $\begin{array}{l}100 \text { francs }= \\
1 \text { US dollar }\end{array}$ \\
\hline Experience & no & no & no & no & no & no & yes \\
\hline
\end{tabular}


Table 2.A: Predictions of Implicit Prices: NOT SETS Information Condition, $\mathrm{K}=3$, and (sx) is the State.

\begin{tabular}{lccc}
\hline & $\mathrm{P}_{\mathrm{sx}}$ & $\mathrm{P}_{\mathrm{sy}}$ & $\mathrm{P}_{\mathrm{sz}}$ \\
\hline $\begin{array}{l}\text { Proportional } \\
\text { Allocation / Decision } \\
\text { Theoretic Private }\end{array}$ & 0.5 & 0.25 & 0.25 \\
Information & & & \\
\hline $\begin{array}{l}\text { Competitive } \\
\text { Equilibrium Private }\end{array}$ & 0.333 & 0.333 & 0.333 \\
Information & 0 & 0 \\
\hline $\begin{array}{l}\text { Competitive } \\
\text { Equilibrium Rational } \\
\text { Expectations }\end{array}$ & 1 & 0 & \\
\hline
\end{tabular}

Table 2.B: Predictions of Implicit Prices: NOT SETS Conditions, $K=6$, and (sx) is the State.

\begin{tabular}{lcccccc}
\hline & $\mathrm{P}_{\mathrm{sx}}$ & $\mathrm{P}_{\mathrm{sv}}$ & $\mathrm{P}_{\mathrm{sz}}$ & $\mathrm{P}_{\mathrm{tx}}$ & $\mathrm{P}_{\mathrm{tv}}$ & $\mathrm{P}_{\mathrm{tz}}$ \\
\hline $\begin{array}{l}\text { Proportional } \\
\begin{array}{l}\text { Allocation / Decision } \\
\text { Theoretic Private } \\
\text { Information }\end{array}\end{array}$ & 0.278 & 0.194 & 0.194 & 0.167 & 0.083 & 0.083 \\
\hline $\begin{array}{l}\text { Competitive } \\
\begin{array}{l}\text { Equilibrium Private } \\
\text { Information }\end{array}\end{array}$ & 0.167 & 0.167 & 0.167 & 0.167 & 0.167 & 0.167 \\
\hline $\begin{array}{l}\text { Competitive } \\
\text { Equilibrium Rational } \\
\text { Expectations (AIA) }\end{array}$ & 1 & 0 & 0 & 0 & 0 & 0 \\
\hline
\end{tabular}


Table 2.C: Predictions of Competitive Equilibrium Private Information model.: Implicit Prices under Probabilistic Information Conditions

\begin{tabular}{lcccccc}
\hline & $\mathrm{P}_{\mathrm{SX}}$ & $\mathrm{P}_{\mathrm{SY}}$ & $\mathrm{P}_{\mathrm{SZ}}$ & $\mathrm{P}_{\mathrm{TX}}$ & $\mathrm{P}_{\mathrm{TY}}$ & $\mathrm{P}_{\mathrm{TZ}}$ \\
\hline Period 17, 112995 & 0.167 & 0.250 & 0.139 & 0.139 & 0.167 & 0.139 \\
\hline Period 18, 112995 & 0.142 & 0.142 & 0.141 & 0.350 & 0.083 & 0.142 \\
\hline Period 17, 113095 & 0.146 & 0.267 & 0.147 & 0.146 & 0.147 & 0.147 \\
\hline Period 18, 113095 & 0.150 & 0.150 & 0.250 & 0.150 & 0.150 & 0.150 \\
\hline Period 1, 121595 & 0.150 & 0.286 & 0.115 & 0.100 & 0.200 & 0.150 \\
\hline Period 2, 121595 & 0.195 & 0.195 & 0.100 & 0.194 & 0.122 & 0.195 \\
\hline Period 3, 121595 & 0.286 & 0.114 & 0.150 & 0.150 & 0.150 & 0.150 \\
\hline Period 4, 121595 & 0.150 & 0.150 & 0.200 & 0.167 & 0.167 & 0.167 \\
\hline Period 5, 121595 & 0.167 & 0.100 & 0.300 & 0.200 & 0.067 & 0.166 \\
\hline Period 6, 121595 & 0.167 & 0.167 & 0.167 & 0.167 & 0.167 & 0.167 \\
\hline Period 7, 121595 & 0.160 & 0.160 & 0.160 & 0.160 & 0.160 & 0.200 \\
\hline Period 8, 121595 & 0.100 & 0.150 & 0.100 & 0.143 & 0.357 & 0.150 \\
\hline Period 9, 121595 & 0.095 & 0.238 & 0.238 & 0.095 & 0.238 & 0.095 \\
\hline Period 10, 121595 & 0.160 & 0.160 & 0.160 & 0.160 & 0.160 & 0.200 \\
\hline Period 11,121595 & 0.100 & 0.133 & 0.333 & 0.150 & 0.133 & 0.150 \\
\hline Period 12, 121595 & 0.154 & 0.167 & 0.167 & 0.166 & 0.100 & 0.246 \\
\hline Period 13,121595 & 0.190 & 0.150 & 0.200 & 0.150 & 0.119 & 0.190 \\
\hline Period 14, 121595 & 0.200 & 0.200 & 0.150 & 0.150 & 0.100 & 0.200 \\
\hline Period 15, 121595 & 0.140 & 0.300 & 0.140 & 0.140 & 0.140 & 0.140 \\
\hline Period 16, 121595 & 0.286 & 0.150 & 0.150 & 0.150 & 0.150 & 0.114 \\
\hline
\end{tabular}


Table 2.D: Predictions of the Competitive Equilibrium Rational Expectations Model: Implicit Prices under Probabilistic Information Conditions

\begin{tabular}{lcccccc}
\hline & $\mathrm{P}_{\mathrm{SX}}$ & $\mathrm{P}_{\mathrm{SY}}$ & $\mathrm{P}_{\mathrm{SZ}}$ & $\mathrm{P}_{\mathrm{TX}}$ & $\mathrm{P}_{\mathrm{TY}}$ & $\mathrm{P}_{\mathrm{TZ}}$ \\
\hline Period 17, 112995 & 0.002 & 0.989 & 0.001 & 0.000 & 0.004 & 0.004 \\
\hline Period 18, 112995 & 0.000 & 0.000 & 0.000 & 1.000 & 0.000 & 0.000 \\
\hline Period 17, 113095 & 0.010 & 0.961 & 0.025 & 0.001 & 0.000 & 0.004 \\
\hline Period 18, 113095 & 0.000 & 0.001 & 0.998 & 0.000 & 0.001 & 0.000 \\
\hline Period 1, 121595 & 0.001 & 0.926 & 0.004 & 0.001 & 0.059 & 0.009 \\
\hline Period 2, 121595 & 0.113 & 0.113 & 0.001 & 0.045 & 0.018 & 0.709 \\
\hline Period 3, 121595 & 0.999 & 0.000 & 0.001 & 0.000 & 0.000 & 0.000 \\
\hline Period 4, 121595 & 0.004 & 0.027 & 0.418 & 0.418 & 0.067 & 0.067 \\
\hline Period 5, 121595 & 0.156 & 0.001 & 0.390 & 0.390 & 0.000 & 0.062 \\
\hline Period 6, 121595 & 0.030 & 0.475 & 0.012 & 0.005 & 0.002 & 0.475 \\
\hline Period 7, 121595 & 0.010 & 0.004 & 0.004 & 0.010 & 0.001 & 0.972 \\
\hline Period 8, 121595 & 0.000 & 0.010 & 0.000 & 0.000 & 0.990 & 0.000 \\
\hline Period 9, 121595 & 0.000 & 0.001 & 0.002 & 0.000 & 0.998 & 0.000 \\
\hline Period 10, 121595 & 0.002 & 0.002 & 0.002 & 0.060 & 0.004 & 0.932 \\
\hline Period 11, 121595 & 0.000 & 0.000 & 0.999 & 0.001 & 0.000 & 0.001 \\
\hline Period 12, 121595 & 0.002 & 0.004 & 0.010 & 0.010 & 0.002 & 0.973 \\
\hline Period 13, 121595 & 0.018 & 0.003 & 0.279 & 0.001 & 0.003 & 0.697 \\
\hline Period 14, 121595 & 0.002 & 0.994 & 0.000 & 0.000 & 0.000 & 0.004 \\
\hline Period 15, 121595 & 0.004 & 0.903 & 0.058 & 0.023 & 0.004 & 0.009 \\
\hline Period 16, 121595 & 0.991 & 0.002 & 0.001 & 0.004 & 0.002 & 0.001 \\
\hline
\end{tabular}

Table 2.E: Predictions of the Proportional Allocation Model: Implicit Prices under Probabilistic Information Conditions

\begin{tabular}{lcccccc}
\hline & $\mathrm{P}_{\mathrm{SX}}$ & $\mathrm{P}_{\mathrm{SY}}$ & $\mathrm{P}_{\mathrm{SZ}}$ & $\mathrm{P}_{\mathrm{TX}}$ & $\mathrm{P}_{\mathrm{TY}}$ & $\mathrm{P}_{\mathrm{TZ}}$ \\
\hline Period 17, 112995 & 0.160 & 0.262 & 0.137 & 0.125 & 0.159 & 0.157 \\
\hline Period 18, 112995 & 0.171 & 0.161 & 0.105 & 0.358 & 0.091 & 0.113 \\
\hline Period 17, 113095 & 0.157 & 0.244 & 0.177 & 0.151 & 0.115 & 0.156 \\
\hline Period 18, 113095 & 0.139 & 0.168 & 0.268 & 0.140 & 0.148 & 0.138 \\
\hline Period 1, 121595 & 0.114 & 0.263 & 0.137 & 0.111 & 0.205 & 0.169 \\
\hline Period 2, 121595 & 0.185 & 0.183 & 0.101 & 0.168 & 0.139 & 0.224 \\
\hline Period 3, 121595 & 0.314 & 0.116 & 0.162 & 0.119 & 0.142 & 0.147 \\
\hline Period 4, 121595 & 0.117 & 0.141 & 0.214 & 0.201 & 0.157 & 0.170 \\
\hline Period 5, 121595 & 0.193 & 0.099 & 0.237 & 0.220 & 0.085 & 0.166 \\
\hline Period 6, 121595 & 0.170 & 0.213 & 0.146 & 0.144 & 0.117 & 0.210 \\
\hline Period 7, 121595 & 0.162 & 0.145 & 0.145 & 0.172 & 0.119 & 0.258 \\
\hline Period 8, 121595 & 0.126 & 0.207 & 0.099 & 0.111 & 0.319 & 0.137 \\
\hline Period 9, 121595 & 0.104 & 0.159 & 0.188 & 0.104 & 0.342 & 0.104 \\
\hline Period 10, 121595 & 0.130 & 0.130 & 0.130 & 0.185 & 0.157 & 0.268 \\
\hline Period 11, 121595 & 0.111 & 0.123 & 0.319 & 0.167 & 0.111 & 0.169 \\
\hline Period 12, 121595 & 0.125 & 0.157 & 0.158 & 0.153 & 0.140 & 0.268 \\
\hline Period 13,121595 & 0.169 & 0.125 & 0.220 & 0.114 & 0.138 & 0.234 \\
\hline Period 14, 121595 & 0.174 & 0.284 & 0.131 & 0.131 & 0.104 & 0.176 \\
\hline Period 15, 121595 & 0.126 & 0.267 & 0.169 & 0.170 & 0.128 & 0.140 \\
\hline Period 16, 121595 & 0.285 & 0.147 & 0.133 & 0.159 & 0.147 & 0.128 \\
\hline
\end{tabular}


Table 3: Average Implicit Price and Relative Frequency of Winning Given Rank in the NOT SETS Information Condition: Rank Determined by Implicit Price.

\begin{tabular}{l|l|l|l|l}
\hline $\begin{array}{l}\text { Market } \\
\text { Rank } \\
\text { by } \\
\text { Implicit } \\
\text { Price }\end{array}$ & Prerage Implicit & $\begin{array}{l}\text { Relative Frequency of } \\
\text { Winning given Rank } \\
\text { Objective winning }\end{array}$ & $\begin{array}{l}\text { Standard error } \\
\text { of Relative } \\
\text { Frequency of } \\
\text { Winning } \\
\text { probability) } \\
(3)\end{array}$ & t-statistic \\
\hline 1st & 0.744 & 0.763 & 0.069 & {$[(2)-(3)] /(4)$} \\
\hline 2nd & 0.161 & 0.132 & 0.055 & 0.280 \\
\hline 3rd & 0.055 & 0.053 & 0.036 & 0.064 \\
\hline 4th & 0.023 & 0.026 & 0.026 & -0.128 \\
\hline 5th & 0.012 & 0.026 & 0.026 & -0.563 \\
\hline 6th & 0.005 & 0.000 & 0.000 & - \\
\hline Number of periods included is 38 & & &
\end{tabular}

Table 4: Average Implicit Price and Relative Frequency of Winning Given Rank in Probabilistic Information Conditions: Rank Determined by Implicit Price.

\begin{tabular}{l|l|l|l|l}
\hline $\begin{array}{l}\text { Market } \\
\text { Rank } \\
\text { by } \\
\text { Implicit } \\
\text { Price }\end{array}$ & $\begin{array}{l}\text { Average Implicit } \\
\text { Price given Rank }\end{array}$ & $\begin{array}{l}\text { Relative Frequency of } \\
\text { Winning given Rank } \\
\text { (Objective winning } \\
\text { probability) } \\
(3)\end{array}$ & $\begin{array}{l}\text { Standard error } \\
\text { of Relative } \\
\text { Frequency of } \\
\text { Winning } \\
(4)\end{array}$ & t-statistic \\
\hline 1st & 0.536 & 0.588 & 0.060 & -0.871 \\
\hline 2nd & 0.217 & 0.235 & 0.051 & -0.356 \\
\hline 3rd & 0.109 & 0.074 & 0.032 & 1.125 \\
\hline 4th & 0.063 & 0.059 & 0.029 & 0.138 \\
\hline 5th & 0.043 & 0.029 & 0.020 & 0.658 \\
\hline 6th & 0.032 & 0.015 & 0.015 & 1.181 \\
\hline
\end{tabular}

Number of periods included is 68 .

Table 5: Estimated Coefficient of $\beta$ in the Model $\mathrm{W}_{\mathrm{i}}=\alpha_{\mathrm{i}}+\beta \mathrm{P}\left(\mathrm{s} \mid \mathrm{x}_{\mathrm{i}}\right)+\varepsilon_{\mathrm{i}}$ (t-values): Relation Between Profits and Inside Information.

\begin{tabular}{l|c}
\hline Information Structure & Estimated coefficient $\beta$ \\
\hline NOT SETS & $344.34(0.86)$ \\
\hline PIC-4 & $1250.95(8.87)$ \\
\hline PIC-2 & $1078.07(10.89)$ \\
\hline
\end{tabular}


Table 6: Average Würtz Distance of Distribution from the AIA Distribution (sample standard deviation).

\begin{tabular}{l|l|l|l|l|l}
\hline & $\begin{array}{l}\text { Dec.Th. } \\
\text { P.I. } \\
\text { Opinion }\end{array}$ & $\begin{array}{l}\text { CEPI } \\
\text { Opinion }\end{array}$ & $\begin{array}{l}\text { Average } \\
\text { Opinion }\end{array}$ & $\begin{array}{l}\text { Best } \\
\text { Opinion }\end{array}$ & $\begin{array}{l}\text { Implicit } \\
\text { Prices }\end{array}$ \\
\hline NOT SETS & 0.722 & 0.833 & 0.722 & 0.667 & 0.331 \\
& $(-)$ & $(-)$ & $(-)$ & $(-)$ & $(0.276)$ \\
\hline PIC-4 & 0.485 & 0.654 & 0.629 & 0.403 & 0.485 \\
& $(0.118)$ & $(0.121)$ & $(0.113)$ & $(0.149)$ & $(0.192)$ \\
\hline PIC-2 & 0.516 & 0.663 & 0.634 & 0.320 & 0.452 \\
& $(0.115)$ & $(0.130)$ & $(0.125)$ & $(0.129)$ & $(0.172)$ \\
\hline
\end{tabular}

Table 7: Average Kullback-Leibler Distance of Distribution from the AIA Distribution (sample standard deviation).

\begin{tabular}{l|l|l|l|l|l}
\hline & $\begin{array}{l}\text { Dec. Th. } \\
\text { P.I. } \\
\text { Opinion }\end{array}$ & $\begin{array}{l}\text { CEPI } \\
\text { Opinion }\end{array}$ & $\begin{array}{l}\text { Average } \\
\text { Opinion }\end{array}$ & $\begin{array}{l}\text { Best } \\
\text { Opinion }\end{array}$ & $\begin{array}{l}\text { Implicit } \\
\text { Prices }\end{array}$ \\
\hline PIC-2 & 1.745 & 2.883 & 2.694 & 1.660 & 1.722 \\
& $(0.833)$ & $(1.428)$ & $(1.380)$ & $(1.594)$ & $(0.815)$ \\
\hline PIC-4 & 2.117 & 3.227 & 2.973 & 1.210 & 1.861 \\
& $(1.084)$ & $(1.562)$ & $(1.530)$ & $(0.659)$ & $(1.224)$ \\
\hline
\end{tabular}

T'Results of two (four) periods are deleted in the PIC-2 (PIC-4), as the myopic opinion contained probability mass of zero for some market.

Table 8: Average Würtz Measure of Distance of Model Predictions from Implicit Prices (sample standard deviation).

\begin{tabular}{l|l|l|l|l}
\hline & $\begin{array}{l}\text { Decision } \\
\text { Theory } \\
\text { Private } \\
\text { Information }\end{array}$ & $\begin{array}{l}\text { Proportional } \\
\text { Allocation }\end{array}$ & $\begin{array}{l}\text { Competitive } \\
\text { Equilibrium } \\
\text { Private } \\
\text { Information }\end{array}$ & $\begin{array}{l}\text { Competitive } \\
\text { Equilibrium } \\
\text { Rational } \\
\text { Expectations } \\
\text { (AIA) }\end{array}$ \\
\hline NOT SETS & 0.523 & 0.523 & 0.620 & 0.331 \\
& $(0.103)$ & $(0.103)$ & $(0.121)$ & $(0.276)$ \\
\hline PIC-4 & 0.275 & 0.332 & 0.342 & 0.485 \\
& $(0.102)$ & $(0.101)$ & $(0.098)$ & $(0.192)$ \\
\hline PIC-2 & 0.301 & 0.366 & 0.392 & 0.452 \\
& $(0.103)$ & $(0.086)$ & $(0.090)$ & $(0.172)$ \\
\hline
\end{tabular}


Table 9: Average Kullback-Leibler Measure of Distance of Model

Predictions from Implicit Prices (sample standard deviation).

\begin{tabular}{l|l|l|l|l}
\hline & $\begin{array}{l}\text { Decision } \\
\text { Theory } \\
\text { Private } \\
\text { Information }\end{array}$ & $\begin{array}{l}\text { Proportional } \\
\text { Allocation }\end{array}$ & $\begin{array}{l}\text { Competitive } \\
\text { Equilibrium } \\
\text { Private } \\
\text { Information }\end{array}$ & $\begin{array}{l}\text { Competitive } \\
\text { Equilibrium } \\
\text { Rational } \\
\text { Expectations } \\
\text { (AIA) }\end{array}$ \\
\hline PIC-4 & 0.246 & 0.313 & 0.336 & 1.722 \\
& $(0.199)$ & $(0.181)$ & $(0.177)$ & $(0.815)$ \\
\hline PIC-2 & 0.277 & 0.347 & 0.399 & 1.861 \\
& $(0.179)$ & $(0.146)$ & $(0.165)$ & $(1.224)$ \\
\hline
\end{tabular}

${ }^{\mathrm{T}}$ Results of two (four) periods are deleted in PIC-4 (PIC-2) as the myopic opinion contained probability mass of zero for some market.

Table 10: Average Investment in Tickets Per Period as a Percentage of the Maximum Possible.

\begin{tabular}{l|l|l|l|l|l|l|l}
\hline & 111995 & 112995 & 113095 & 121595 & $061896 \mathrm{~A}$ & $061896 \mathrm{~B}$ & 061996 \\
\hline NOT SETS & 0.714 & 0.773 & 0.720 & & & & \\
\hline PIC-4 & & 0.753 & 0.618 & 0.617 & & & \\
\hline PIC-2 & & & & & 0.501 & 0.542 & 0.720 \\
\hline
\end{tabular}

Table 11: Average Percentage of Total Volume of Spending that Occurred within Designated Time Periods.

\begin{tabular}{l|l|l|l}
\hline & $\begin{array}{l}\leq 230 \text { seconds from } \\
\text { period open }\end{array}$ & $\begin{array}{l}230-240 \text { seconds } \\
\text { from period open }\end{array}$ & $\begin{array}{l}240 \text { seconds from } \\
\text { period open - end }\end{array}$ \\
\hline 111995 & 0.238 & 0.366 & 0.397 \\
\hline 112995 & 0.114 & 0.117 & 0.769 \\
\hline 113095 & 0.186 & 0.327 & 0.487 \\
\hline 121595 & 0.670 & 0.203 & 0.127 \\
\hline NOT SETS & 0.154 & 0.226 & 0.620 \\
\hline PIC-4 & 0.585 & 0.242 & 0.173 \\
\hline & $\leq 100$ seconds from & $\begin{array}{l}100-140 \text { seconds } \\
\text { from period open }\end{array}$ & $\begin{array}{l}140 \text { seconds from } \\
\text { period open - end }\end{array}$ \\
\hline $061896 \mathrm{~A}$ & period open & 0.420 & 0.335 \\
\hline $061896 \mathrm{~B}$ & 0.245 & 0.422 & 0.414 \\
\hline 061996 & 0.164 & 0.493 & 0.219 \\
\hline PIC-2 & 0.288 & 0.445 & 0.323 \\
\hline
\end{tabular}


Table 12: Strategic Purchases Expressed as a Fraction of the Number of Transactions and as a Fraction of the Amount of Money Involved.

\begin{tabular}{l|l|l}
\hline & $\begin{array}{l}\text { Strategic Purchases as a } \\
\text { Fraction of Total Purchases } \\
\text { (in number of transactions) }\end{array}$ & $\begin{array}{l}\text { Strategic Purchases as a } \\
\text { Fraction of Total Purchases } \\
\text { (in number of francs) }\end{array}$ \\
\hline 111995 & 0.203 & 0.009 \\
\hline 112995 & 0.163 & 0.016 \\
\hline 113095 & 0.191 & 0.028 \\
\hline NOT SETS & 0.181 & 0.020 \\
\hline
\end{tabular}

Table 13: Pearson Correlation Coefficient Between the Number of Strategic Purchases (as a Fraction of the Total Number of Purchases) and the Würtz Measure of Distance of Implicit prices from AIA.

\begin{tabular}{l|l|l|l}
\hline Experiment & 111995 & 112995 & 113095 \\
\hline $\begin{array}{l}\text { Average Pearson } \\
\text { Correlation Coefficient }\end{array}$ & -0.704 & -0.596 & 0.049 \\
\hline
\end{tabular}

Table 14: Average Würtz Measure of Distance of Implicit Prices from AIA at Various Times During Periods. (sample standard deviation).

\begin{tabular}{l|c|c|c}
\hline & $\begin{array}{c}1 / 3 \text { of total bets } \\
\text { realized }\end{array}$ & $\begin{array}{c}2 / 3 \text { of total bets } \\
\text { realized }\end{array}$ & overall \\
\hline NOT SETS & 0.464 & 0.367 & 0.331 \\
& $(0.291)$ & $(0.284)$ & $(0.276)$ \\
\hline PIC-4 & 0.619 & 0.506 & 0.485 \\
& $(0.206)$ & $(0.209)$ & $(0.192)$ \\
\hline PIC-2 & 0.553 & 0.473 & 0.452 \\
& $(0.175)$ & $(0.172)$ & $(0.172)$ \\
\hline
\end{tabular}


Table 15: Average Würtz Distance of Model Predictions from Implicit Prices for Selected Time Periods. (sample standard deviation)

\begin{tabular}{l|l|l|l|l}
\hline & & $\begin{array}{l}1 / 3 \text { of total bets } \\
\text { realized }\end{array}$ & $\begin{array}{l}2 / 3 \text { of total bets } \\
\text { realized }\end{array}$ & overall \\
\hline $\begin{array}{l}\text { Decision } \\
\text { Theory }\end{array}$ & NOT SETS & 0.473 & 0.516 & 0.523 \\
$(0.123)$ & $(0.113)$ & $(0.103)$ \\
\cline { 2 - 5 } $\begin{array}{l}\text { Private } \\
\text { Information }\end{array}$ & PIC-4 & 0.295 & 0.284 & 0.275 \\
& & $(0.096)$ & $(0.106)$ & $(0.102)$ \\
\cline { 2 - 5 } & PIC-2 & 0.269 & 0.290 & 0.301 \\
$(0.104)$ & $(0.102)$ & $(0.103)$ \\
\hline Proportional & NOT SETS & 0.473 & 0.516 & 0.523 \\
& & $(0.123)$ & $(0.113)$ & $(0.103)$ \\
\cline { 2 - 5 } Allocation & PIC-4 & 0.276 & 0.331 & 0.332 \\
& & $(0.105)$ & $(0.086)$ & $(0.101)$ \\
\cline { 2 - 5 } & PIC-2 & 0.286 & 0.344 & 0.366 \\
& & $(0.091)$ & $(0.091)$ & $(0.086)$ \\
\hline Competitive & NOT SETS & 0.566 & 0.613 & 0.620 \\
Equilibrium & & $(0.113)$ & $(0.108)$ & $(0.121)$ \\
\cline { 2 - 5 } $\begin{array}{l}\text { Private } \\
\text { Information }\end{array}$ & PIC-4 & 0.275 & 0.342 & 0.342 \\
& & $(0.120)$ & $(0.083)$ & $(0.098)$ \\
\cline { 2 - 5 } & PIC-2 & 0.311 & 0.369 & 0.392 \\
& & $(0.092)$ & $(0.095)$ & $(0.090)$ \\
\hline Competitive & NOT SETS & 0.464 & 0.367 & 0.331 \\
Equilibrium & & $(0.291)$ & $(0.284)$ & $(0.276)$ \\
Rational & PIC-4 & 0.619 & 0.506 & 0.485 \\
Expectations & & $(0.206)$ & $(0.209)$ & $(0.192)$ \\
\cline { 2 - 5 } & PIC-2 & 0.553 & 0.473 & 0.452 \\
& & $(0.175)$ & $(0.172)$ & $(0.172)$ \\
\hline
\end{tabular}

Table 16: Average Maximum Implicit Price for Selected Time Periods.

\begin{tabular}{c|c|c|c}
\hline & $\begin{array}{c}1 / 3 \text { of total bets } \\
\text { realized }\end{array}$ & $\begin{array}{c}2 / 3 \text { of total bets } \\
\text { realized }\end{array}$ & overall \\
\cline { 2 - 4 } NOT SETS & 0.675 & 0.725 & 0.744 \\
\hline PIC-4 & 0.446 & 0.515 & 0.528 \\
\hline PIC-2 & 0.442 & 0.515 & 0.540 \\
\hline
\end{tabular}


Table 17: Average Minimum Implicit Price for Selected Time Periods.

\begin{tabular}{c|c|c|c}
\hline & $\begin{array}{c}1 / 3 \text { of total bets } \\
\text { realized }\end{array}$ & $\begin{array}{c}2 / 3 \text { of total bets } \\
\text { realized }\end{array}$ & overall \\
\hline NOT SETS & 0.010 & 0.006 & 0.005 \\
\hline PIC-4 & 0.064 & 0.041 & 0.034 \\
\hline PIC-2 & 0.044 & 0.034 & 0.031 \\
\hline
\end{tabular}

Table 18: Average Würtz measure of distance from market prices from AIA at various times during periods.

\begin{tabular}{c|c|c|c}
\hline & $\begin{array}{c}1 / 3 \text { of gross tickets } \\
\text { sales realized }\end{array}$ & $\begin{array}{c}2 / 3 \text { of gross tickets } \\
\text { sales realized }\end{array}$ & overall \\
\hline Period 17, 061996 & 0.906 & 0.856 & 0.843 \\
\hline Period 18,061996 & 0.764 & 0.612 & 0.462 \\
\hline
\end{tabular}


FIGURE 1: Timing of actions

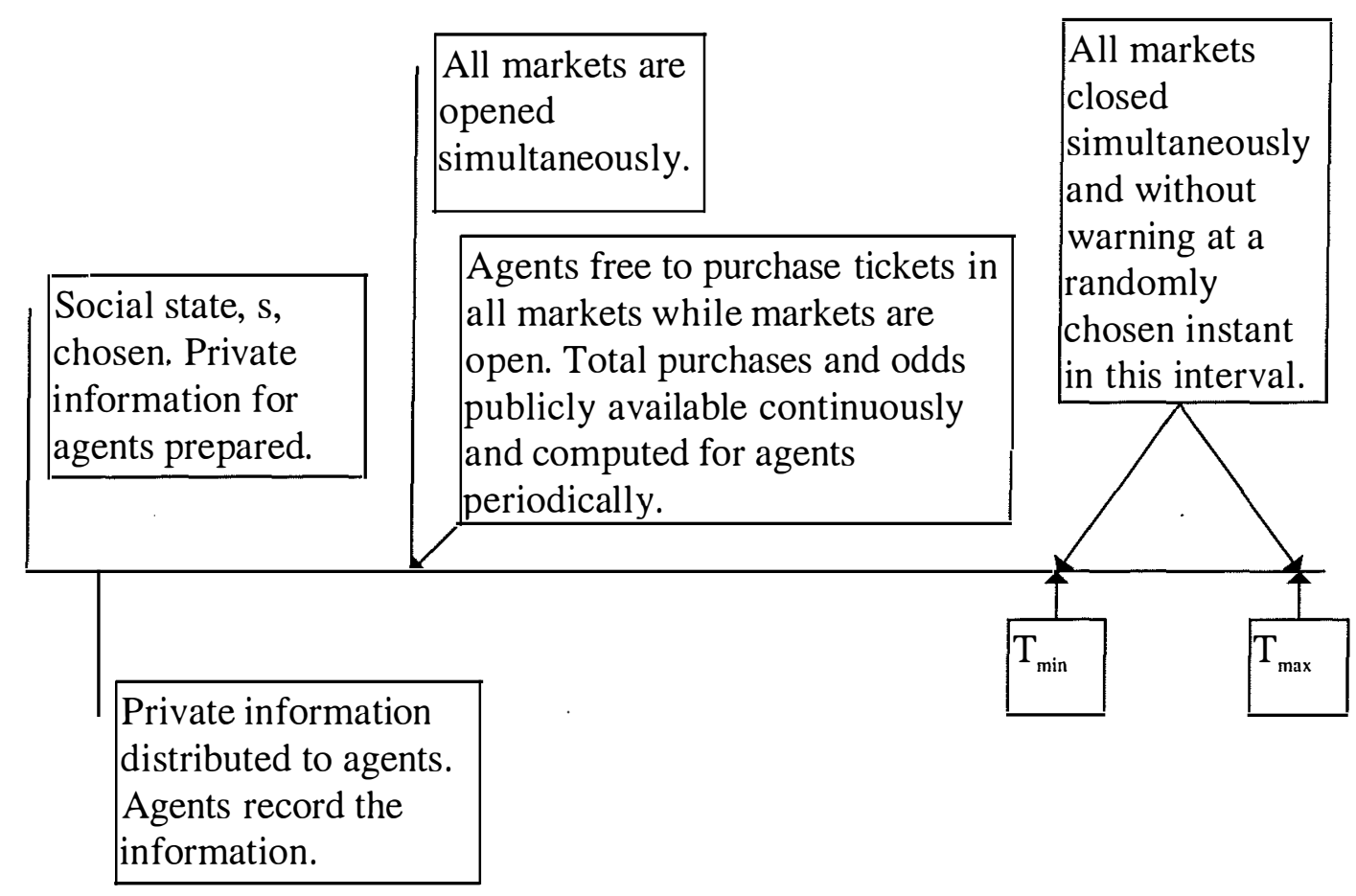


Figure 2-A: Cumulatlve Volume Period 11; 112995

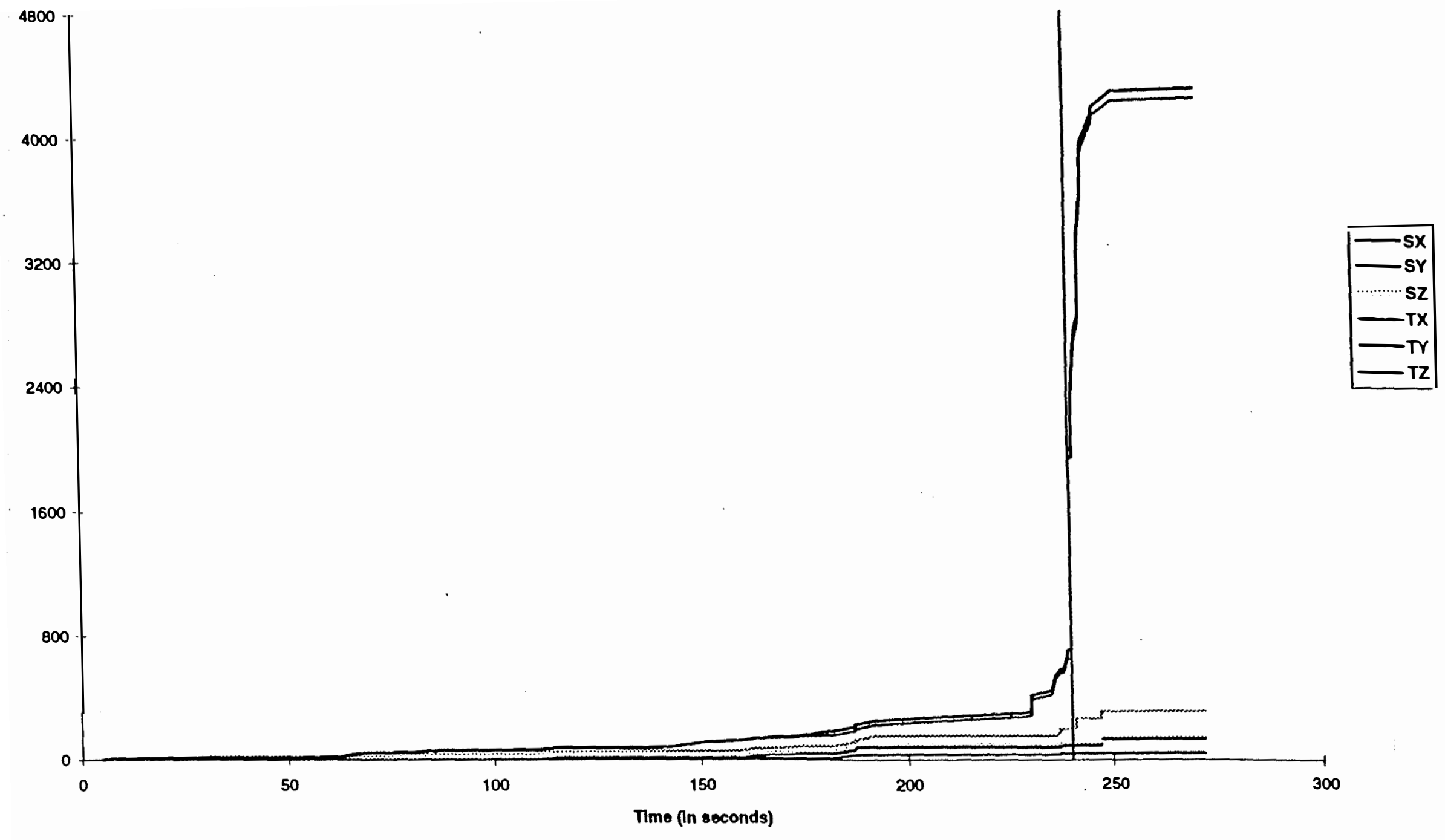


Figure 2-B: Prices Period 11; 112995

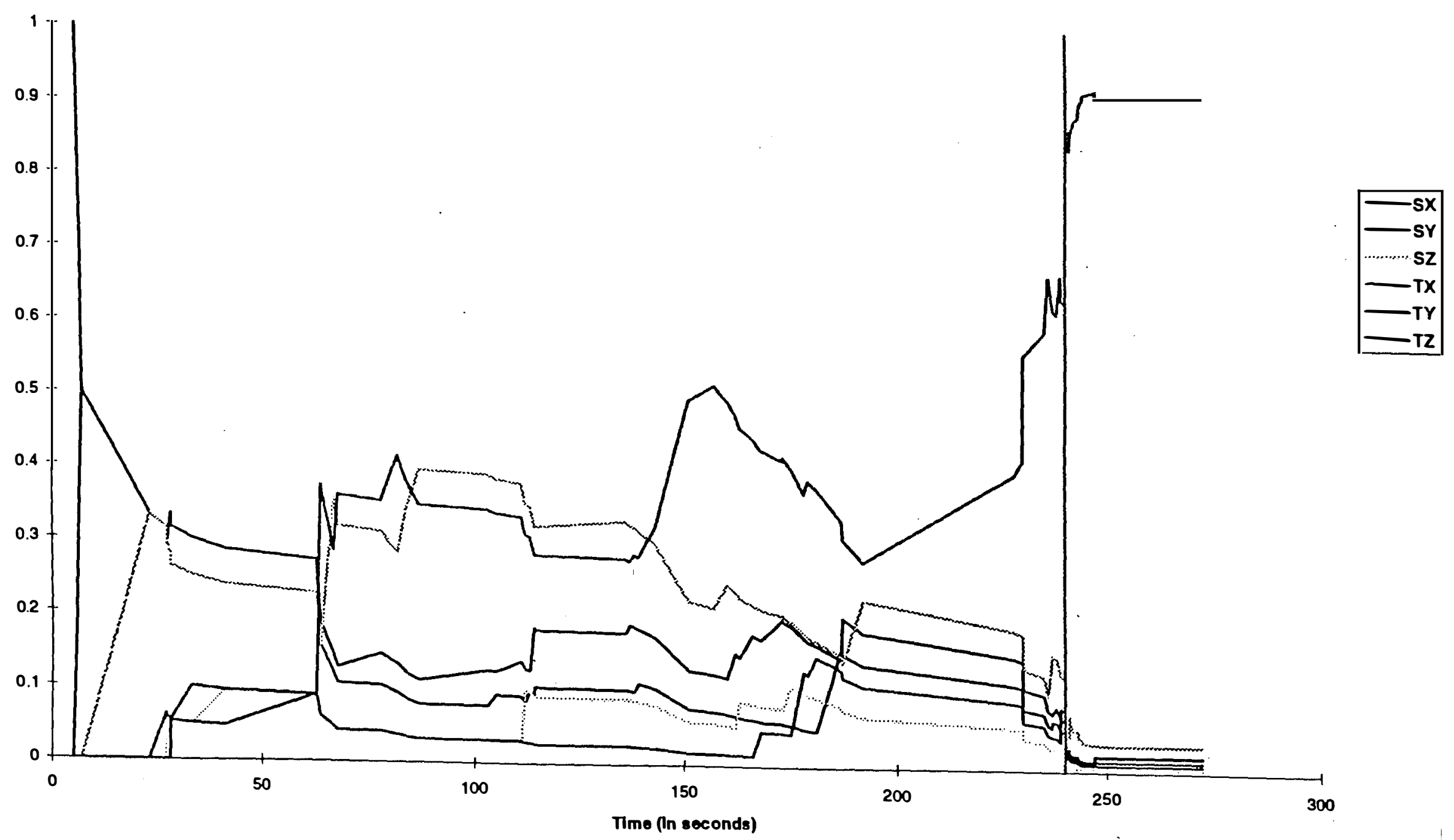


Figure 3-A: Cumulatlve Volume Perlod 11, 113095

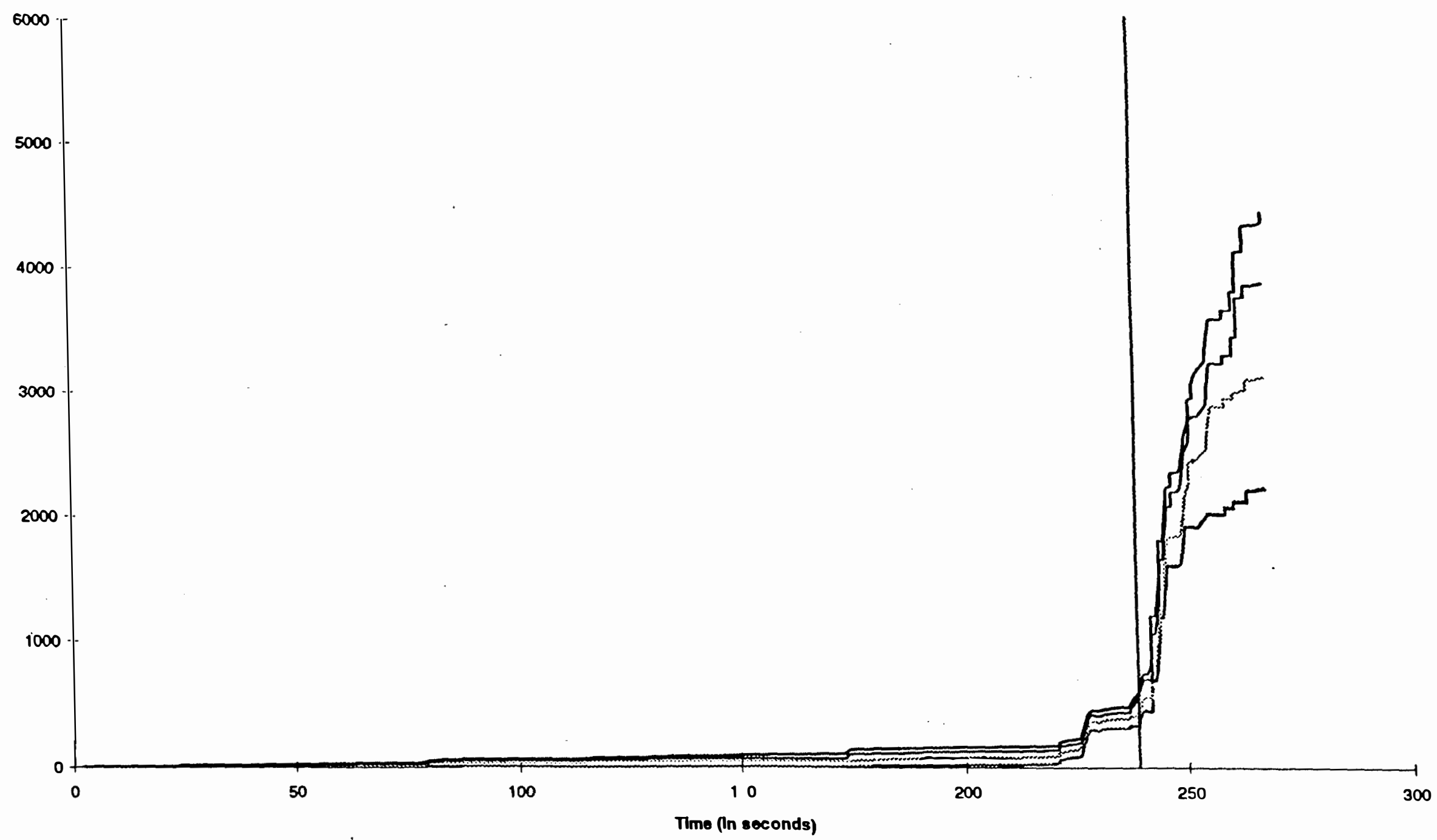


Figure 3-B: Prices Period 11; 113095

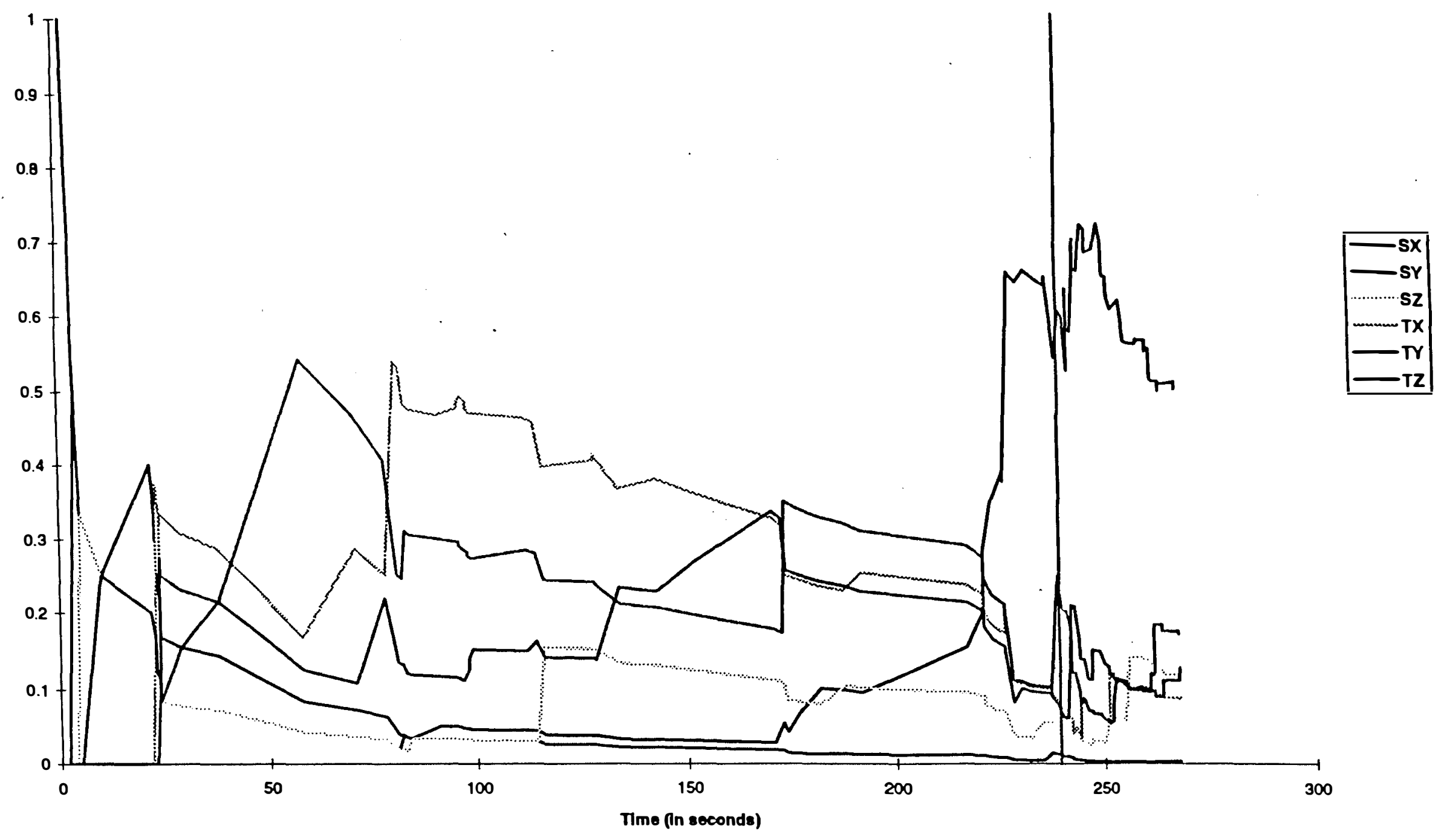

